\title{
PERCEIVED RELATIONSHIP QUALITY IN ADOLESCENTS FOLLOWING EARLY SOCIAL-EMOTIONAL DEPRIVATION
}

\author{
by \\ Brandi Hawk \\ BS, University of Pittsburgh, 2009
}

Submitted to the Graduate Faculty of

The Kenneth P. Dietrich School of Arts and Sciences in partial fulfillment

of the requirements for the degree of

Master of Science

University of Pittsburgh 


\title{
UNIVERSITY OF PITTSBURGH
}

\author{
The Kenneth P. Dietrich School of Arts and Sciences \\ Department of Psychology
}

This thesis was presented

by

Brandi Hawk

It was defended on

March 17, 2011

and approved by

Susan B. Campbell, Professor, Department of Psychology

Celia Brownell, Professor, Department of Psychology

Thesis Chair: Robert B. McCall, Professor, Department of Psychology 
Copyright (C) by Brandi Hawk

2013 


\section{Perceived Relationship Quality in Adolescents Following Early Social-Emotional Deprivation}

Brandi Hawk, M.S.

University of Pittsburgh, 2013

Orphanages in the Russian Federation are deficient primarily in social-emotional relationships (St. Petersburg-USA Orphanage Research Team, 2005). Children who spend their first months or years of life in orphanages have limited opportunities to form relationships and to develop proper social skills. This early experience has been associated with many problematic behavioral outcomes (Gunnar et al., 2007; Rutter et al., 2010). However, researchers have not frequently examined relationship quality of post-institutional (PI) adoptees, nor have they examined aspects of the adoptive family that might moderate institutionalization effects. The purpose of this study was to examine the self-reported relationship quality (using the Network of Relationships Inventory: Social Provisions Version; Furman \& Buhrmester, 1985) of 10-17-yearold children adopted into the USA from Russian orphanages and to determine whether sibling characteristics (relative age, gender composition, sibling adoption status) moderate institutionalization effects. Older age at adoption was related to poorer friendship and sibling, but not mother, relationship quality. Older siblings and same-sex siblings buffered children from this negative age-at-adoption association. 


\section{A.1.1 TABLE OF CONTENTS}

$1.0 \quad$ INTRODUCTION ........................................................................................................ 1

1.1 THEORETICAL BASIS FOR INVESTIGATING POST-INSTITUTIONAL

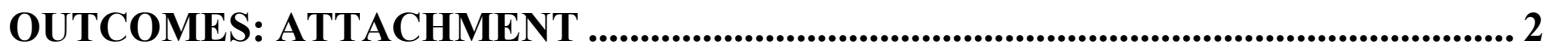

1.1.1 Support for an attachment perspective................................................ 3

I.2 IMPORTANCE OF RELATIONSHIPS WITH MOTHERS, SIBLINGS,

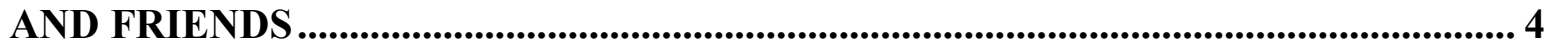

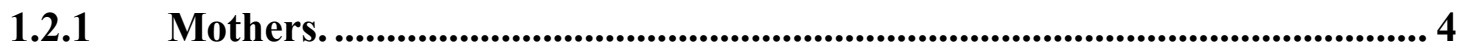

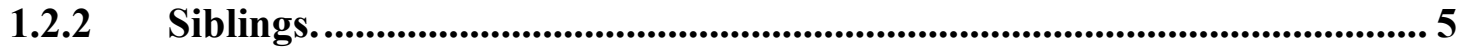

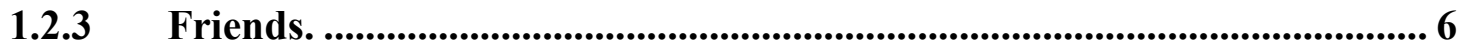

1.3 SIBLING CHARACTERISTICS AS POTENTIAL MODERATORS OF

RELATIONSHIP QUALITY .............................................................................................. 8

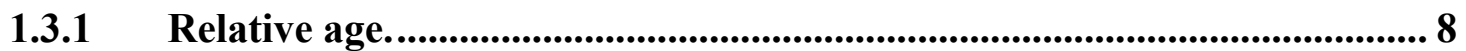

1.3.2 Gender composition....................................................................................... 9

1.3.3 Adoption status of sibling. ................................................................... 10

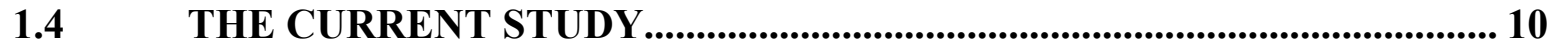

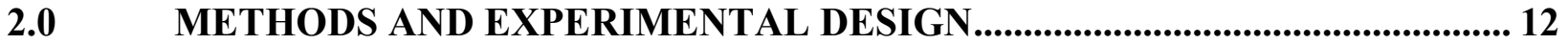

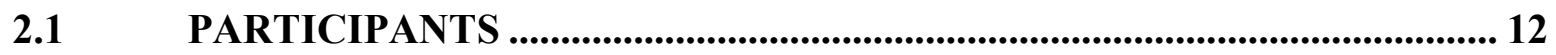

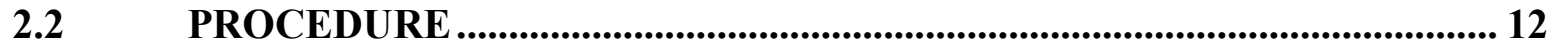

2.2.1 Demographic information.................................................................... 13

2.2.2 Network of Relationships Inventory: Social Provisions Version............ 14 
2.3 SELECTIVE RESPONDING 16

3.0 RESULTS 17

R.1 REATIONSHIP QUALITY IN THE FULL SAMPLE ......................... 17

3.1.1 Comparisons between relationships (main effects).............................. 20

3.1.2 Non-PI versus PI. ........................................................................... 21

3.1.3 Age at assessment and gender......................................................... 22

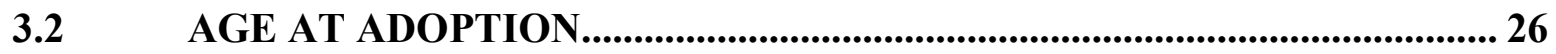

3.2.1 Form of age at adoption. ................................................................. 27

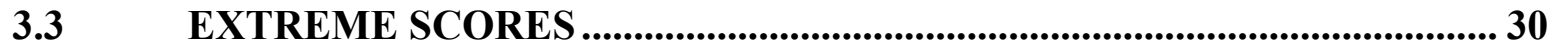

SIBLING CHARACTERISTICS ........................................................... 32

3.4.1 Relative Age................................................................................... 33

3.4.1.1 Mother............................................................................................. 35

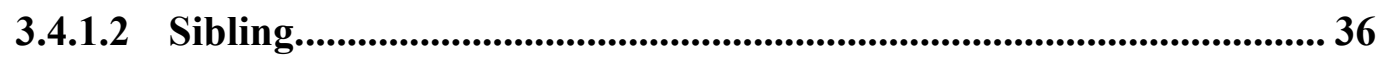

3.4.1.3 Best Friend................................................................................... 36

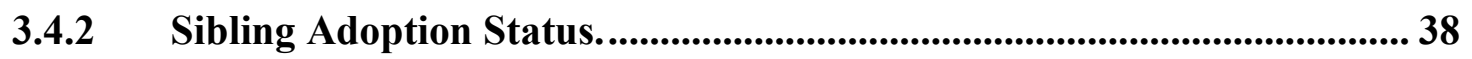

3.4.3 Gender Composition of Sibling Relationship.......................................... 40

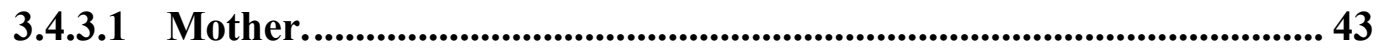

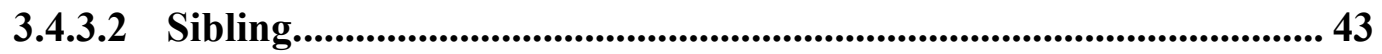

3.4.3.3 Best Friend..................................................................................................... 44

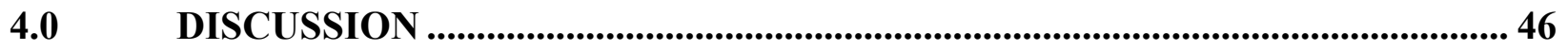

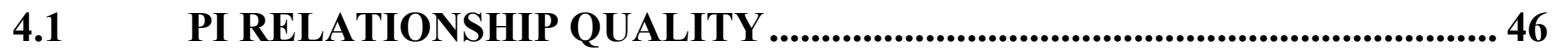

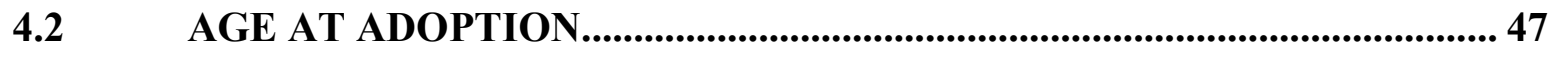




\subsection{SIBLING CHARACTERISTICS: HOW SIBLINGS BUFFER}

INSTITUTIONALIZATION EFFECTS.................................................................... 49

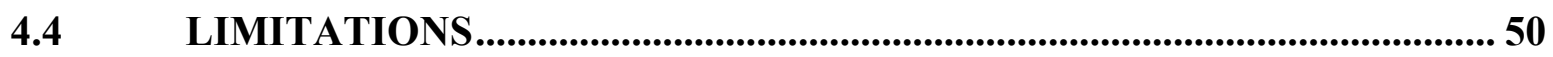

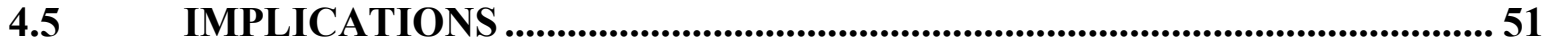

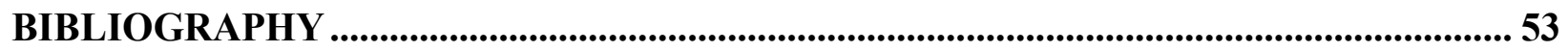




\section{A.1.2 List of tables}

Table 1. Mean (Standard Deviation) Relationship Quality Subscale Scores for each Relationship Type for PI and non-PI (Lempers \& Clarklempers, 1992) Children .................................... 18 Table 2. Mean (Standard Deviation) Relationship Quality by Relationship Source and Age at

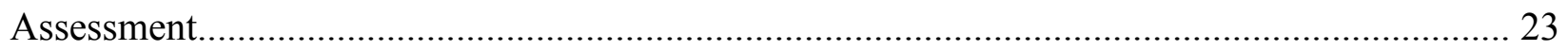

Table 3. Mean (Standard Deviation) Relationship Quality by Relationship Source and Gender. 25 Table 4. R egression Coefficients from Analyses Predicting Relationship Quality with Age at

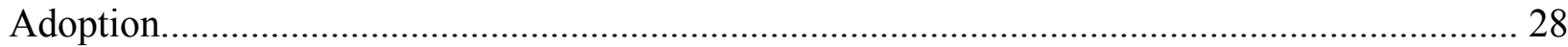

Table 5. Percentage of Children with "Good" and "Bad" Extreme Relationship Quality Scores by Age at Adoption (Months), Age at Assessment (Years), and Gender.................................... 31 Table 6. R egression Coefficients for Analyses Predicting Relationship Quality with Sibling Relative Age (No Sibling, Older Sibling, Younger Sibling)................................................ 33 Table 7. Regression Coefficients for Analyses Predicting Relationship Quality with Sibling Adoption Status (No Sibling, Biological Child, Adopted Child)........................................... 38 Table 8. R egression Coefficients for Analyses Predicting Relationship Quality with Sibling Gender Composition (No Sibling, Opposite Gender, Same Gender). 41 


\section{A.1.3 List of figures}

Figure 1. Relationship quality profiles for PI children's mothers, siblings, and best friends. For positive quality subscales, higher scores indicate better quality (left). For negative quality subscales, higher scores indicate poorer quality (right) ................................................... 21

Figure 2. Linear interaction between age at adoption and gender for best friend Negative Interaction, controlling for age at assessment and the interaction of age at adoption and age at

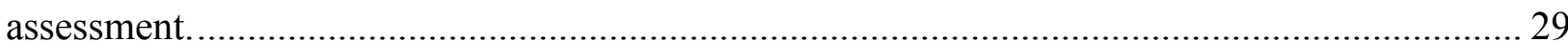

Figure 3. Linear interactions of age at adoption and sibling relative age for mother and sibling social support $($ higher $=$ better) and friend negative interaction (higher $=$ worse), controlling for age at assessment, gender, and interactions among the variables. 37

Figure 4. Linear interactions of age at adoption and sibling gender composition for sibling and best friend social support (higher $=$ better) and sibling negative interaction (higher $=$ worse), controlling for age at assessment, gender, and interactions. 45 


\subsection{INTRODUCTION}

In 2008, approximately 115,000 children in the Russian Federation were living in institutions (Levy, 2010). Of those children, approximately 1500 were adopted to the United States in 2009 (United States Department of State, Office of Children's Issues). Although the quality of institutions varies throughout the country, Baby Homes in St. Petersburg, where most of the children in the current study resided prior to adoption, are selectively social-emotionally depriving, or Gunnar's (2001) level three institutions, meeting all needs except for typical caregiver-child interactions and stable, long-term relationships with consistent caregivers. Such an environment can be expected to be associated with subsequent relationship problems.

Specifically, children receive adequate medical care, sanitation, nutrition, toys, and equipment; however, they experience 60-100 different caregivers during their first 19 months in the institution, and children typically see no caregiver on two consecutive days. Children rarely, if ever, experience warm, sensitive, contingently responsive interactions, and there is little opportunity to form an attachment relationship (The St. Petersburg-USA Orphanage Research Team, 2005, 2008). Indeed, many institutional children are classified as having disorganized attachments (Dobrova-Krol et al., 2010; The St. Petersburg-USA Orphanage Research Team, 2008; Vorria, et al., 2003; Zeanah, Smyke, Koga, \& Carlson, 2005). Thus, research with these children can more specifically address the impact of early social-emotional deprivation, rather than other factors often associated with institutions, on later outcomes. 


\subsection{THEORETICAL BASIS FOR INVESTIGATING POST-INSTITUTIONAL OUTCOMES: ATTACHMENT}

Attachment theory (Ainsworth, Blehar, Waters, \& Wall, 1978; Bowlby, 1982) posits a probabilistic view of development, such that early experience, particularly in an attachment relationship, sets a child on a general path that leads to a set of possibilities rather than a predetermined outcome. The attachment relationship is the child's first experience of emotional closeness, and through consistent, responsive interactions with a few adults, children progressively develop "internal working models" of the purpose and structure of relationships that help them form expectations for the future (Bowlby, 1982; Sroufe, Carlson, Levy, \& Egeland, 1999). Although children's models and expectations can change with experience, they enter each new relationship with learned dispositions that influence their interpretation of situations and interactions. Thus, the longer the child remains in a maladaptive situation, the more difficult it becomes to return to positive functioning (Sroufe et al., 1999).

In the institution, high children-to-caregiver ratios (approximately 5-7: 1 during daytime and 9-14: 1 at night), age-based transitions (approximately two or three transitions by 2 years), high staff turnover, and inconsistent staff schedules (generally 10-24 hours 2-3 times per week, with 52-56 days of vacation per year), create an environment in which forming an attachment is all but impossible (Chisholm, 1998; The St. Petersburg-USA Orphanage Research Team, 2005). The inconsistency and emotional neglect from caregivers may contribute to problems with emotion regulation, including suppressing negative emotions and displaying positive emotions even in stressful situations (Cassidy, 1994; Bakermans-Kranenburg et al., in press). The lack of contingent interactions with a stable caregiver may be related to decreased emotional and behavioral control, including effortful attention regulation and inhibitory control (Bakermans- 
Kranenburg et al., in press; Dobrova-Krol, Bakermans-Kranenburg, van IJzendoorn, \& Juffer, 2010).

\subsubsection{Support for an attachment perspective.}

Attachment to a caregiver and responsive caregiving are theorized to support early behavioral, cognitive, and social development in non-PI children (Ainsworth, et al., 1978); and insecure attachment, especially when disorganized, is related to poorer outcomes in these areas (Carlson, 1998; Shaw, Owens, Vondra, Keenan, \& Winslow, 1997; Sroufe et al., 1999). Research has also established a connection between extended institutional experience, as assessed by age at adoption, and behavior problems (e.g., Gunnar, Van Dulmen, \& The International Adoption Project Team, 2007; Hawk \& McCall, in press; Rutter et al., 2010), executive functioning problems (Bruce, Tarullo, \& Gunnar, 2009; Merz \& McCall, in press; Pollak et al., in press), and social difficulties (Ames, 1997; Gunnar et al., 2007; Julian, 2010; Rutter, Kreppner, \& O'Connor, 2001) in childhood and adolescence.

Deficient early social-emotional experience and lack of relationships in the institutions are hypothesized to be especially important to the quality of important relationships (e.g., mother, sibling, and best friend). One study (Vorria, Wolkind, Rutter, Pickles, \& Hobsbaum, 1998) found that the lack of responsive, individualized care from a consistent caregiver, not physical deficiencies, resulted in more emotional disturbances and less harmonious, intimate relationships with peers in currently institutionalized children than children raised by their biological parents (non-PI). Studies have also found that longer time spent in the institution is associated with less secure attachment to adoptive mother (Bakermans-Kranenburg et al., in 
press; Chisholm, 1998; Juffer \& Rosenboom, 1997; van den Dries, van IJzendoorn, \& Bakermans-Kranenburg, 2009).

Unfortunately, relationship quality in older PI children and adolescents has not been adequately addressed, even though relationship quality may be the domain of functioning most related to social-emotional deprivation and lack of attachment relationship. One relevant study found that later adoption was associated with poorer self-reported support from a best friend (Le Mare, Warford, \& Fernyhough, 2001).

\subsection{IMPORTANCE OF RELATIONSHIPS WITH MOTHERS, SIBLINGS, AND FRIENDS}

\subsubsection{Mothers.}

Although most research focuses on e arly mother-child relationships, the quality of this relationship remains important throughout adolescence. Non-PI children tend to rate their maternal relationships high in reliable alliance, affection, enhancement of worth, instrumental help, intimacy, and satisfaction, but quality decreases in adolescence (Furman \& Buhrmester, 1985b, 1992; Lempers \& Clarklempers, 1992). Adolescents' perceptions of high quality relationships with mothers have been associated with lower levels of adolescent depression (Aseltine, Gore, \& Colten, 1998) and delinquent behaviors (Branstetter, Furman, \& Cottrell, 2009; Hair, Moore, Garrett, Kinukawa, Lippman, \& Michelson, 2005; Hair, Moore, Garrett, Ling, \& Cleveland, 2008; Mason, Cauce, Gonzales, \& Hiraga, 1994), higher levels of mental 
well-being (Armsden \& Greenberg, 1987; Hair et al., 2008), and increased friendship quality (Kerns, Klepac, \& Cole, 1996; Lieberman, et al., 1999).

Very little research has examined mother-adolescent relationships in adoptees. Institutionalization has been associated with poorer mother-child relationships in early childhood, although most young PI children have good relationships with their adoptive mothers (Bakermans-Kranenburg et al., in press; Chisholm, 1998; Juffer \& Rosenboom, 1997; van den Dries, et al., 2009). One study found that a similar proportion of PI and non-PI adolescents had positive relationships with their adoptive or biological mothers (Hodges \& Tizard, 1989). Conversely, adoptive mothers of non-institutionalized domestic adoptees have reported more disagreements with their adolescents than biological mothers or stepmothers (Lansford, Ceballo, Abbey, \& Stewart, 2001).

\subsubsection{Siblings.}

In studies of non-PI children, sibling relationships are exemplified by high levels of conflict, along with affection, alliance, companionship, intimacy, and nurturance (Furman \& Buhrmester, 1985a,b, 1992; Lempers \& Clarklempers, 1992). This environment of simultaneous closeness and conflict theoretically allows children to test and to develop social skills necessary for maintaining other relationships (Furman \& Buhrmester, 1985a). Specifically, positive sibling relationships are linked to behaviors necessary for high quality friendships, including better conflict resolution strategies (Franco \& Levitt, 1998; Recchia \& Howe, 2009), higher levels of companionship and recreation with friends (Franco \& Levitt, 1998), increased self-disclosure (Howe, Aquan-Assee, Bukowski, Lehoux, \& Rinaldi, 2001), increased reciprocal interactions (e.g., companionship, emotional responsiveness, and prosocial activities: Karos, Howe, \& 
Aquan-Assee, 2007), and, for girls, more emotional understanding (Howe et al., 2001). Further, positive sibling relationships have been directly related to increased friendship quality in middle childhood and early adolescence (Franco \& Levitt, 1998; Yeh \& Lempers, 2004).

The only study of PI adolescents' sibling relationships reported more difficulties with siblings for PI children than non-PI comparisons (Hodges \& Tizard, 1989). Among noninstitutionalized domestic adoptees, no difference was found in relationship quality between adoptees and their non-adopted siblings and two biological non-adopted siblings (McGue et al., 2007). Behaviorally, PI children adopted as sibling groups have higher ages at adoption but have lower or similar rates of behavior problems compared to single adoptees (Boer, Versluis-den Bieman, \& Verhulst, 1994; Van den Oord, Boomsma, \& Verhulst, 1994), and similar patterns are found for domestic adoptees (Erich \& Leung, 2002; Hegar, 2005). This finding suggests a protective effect of having a sibling because older age at adoption is generally related to more, not fewer, behavior problems (Cederblad et al., 1999; Gunnar et al., 2007; Rutter et al., 2010). Further, social-emotionally deprived PI children may benefit more from additional interactions with siblings than non-PI children because of their limited earlier relationship experience.

\subsubsection{Friends.}

Approximately $78 \%$ of non-PI children in middle childhood have at least one best friend (Parker \& Asher, 1993), and the best friend relationship is exemplified by companionship, intimacy, enhancement of worth, and some conflict (Furman \& Buhrmester, 1985b; Lempers \& Clarklempers, 1992). In adolescence, friendships tend to be high in support, intimacy, and affection, with some decreases in companionship and nurturance with age (Furman \&

Buhrmester, 1992; Lempers \& Clarklempers, 1992). These findings may be qualified by 
sociometric status, such that high- and average-accepted children have more supportive and intimate friendships and are more satisfied with their friendships than low-accepted children (Parker \& Asher, 1993). However, low-accepted children show the greatest variability in friendship quality (Parker \& Asher, 1993), suggesting that some low-accepted children have very satisfying friendships, but perhaps with only one or two close friends.

Poor friendship quality in non-PI children has been related to loneliness (Nangle, Erdley, Newman, Mason, \& Carpenter, 2003), depression (Nangle et al., 2003), high school dropout rates (Parker \& Asher, 1987), behavior problems (Hartup, 1995), and criminality (Parker \& Asher, 1987). Conversely, high quality friendships are related to school involvement, higher grades, and social competency (Hartup, 1995; Gifford-Smith \& Brownell, 2003). Further, children and adolescents who have at least one supportive friend are more involved in school (Berndt \& Keefe, 1995), are more popular and socially competent, achieve higher grades, and have fewer behavior problems than those with no supportive friends (Hartup, 1995).

PI adolescents who spent more than $24 \mathrm{~m}$ onths in a globally depriving Romanian institution reported less support from a close friend than non-PI children, early-adopted noninstitutionalized Romanian controls, and PI children adopted before 24 months (Le Mare et al., 2001). Hodges and Tizard (1989) also found PI children to be less popular and less likely to confide in friends than non-PI comparisons. Indirectly, several studies that use parent-reported measures of children's social problems, which are likely related to friendship quality, find that PI children have more reported social problems (Hoksbergen, Rijk, Van Dijkum, \& Laak, 2004; Stams, Juffer, Rispens, \& Hoksbergen, 2000; Verhulst, Althaus, \& Versluis-Den Bieman, 1990) and disinhibited social behaviors (Bruce, et al., 2009) than non-PI children. Also, later adopted PI children ( $>7-24$ months at adoption) tend to have more parent-reported social problems than 
earlier adoptees (Cederblad, et al., 1999; Gunnar et al., 2007; Hawk \& McCall, in press; Julian, 2010). These studies suggest that more exposure to institutions with deficient social-emotional relationships, few contingent-responsive interactions, and few opportunities to learn appropriate social skills, is related to more social and friendship problems.

\subsection{SIBLING CHARACTERISTICS AS POTENTIAL MODERATORS OF RELATIONSHIP QUALITY}

Sibling relationships may be especially important contributors to social skills and friendship quality (see above; Franco \& Levitt, 1998; Yeh \& Lempers, 2004). Certain characteristics of siblings have been associated with enhanced relationship quality in non-PI children; however, essentially nothing is known about these factors among PI children.

\subsubsection{Relative age.}

Among non-PI children, there are benefits of having an older rather than a younger sibling. NonPI children with older siblings report greater admiration, intimacy, affection, and prosocial behavior in their sibling relationships than children with younger siblings (Buhrmester \& Furman, 1990); however, companionship may be greater with closely spaced younger siblings (Furman \& Buhrmester, 1985a). Similarly, although antagonism and conflict are generally high in sibling relationships, these negative interactions decrease with age for children with older siblings but not for those with younger siblings (Buhrmester \& Furman, 1990). Karos et al. 
(2007) found that both the negative correlation between rivalry and reciprocal interactions and the positive correlation between reciprocal interactions and socio-emotional problem solving in the sibling relationship was seen only for children with older siblings.

Further, children have reported that parents favor younger siblings (Furman \& Buhrmester, 1985a), suggesting that relationship quality with mother may be higher for children with older than younger siblings. Similarly, because high quality sibling relationships are associated with positive friendships and social skills (Recchia et al., 2009; Yeh \& Lempers, 2004) and having an older sibling is associated with better sibling relationship quality (Buhrmester \& Furman, 1990; Furman \& Burhmester, 1985a), it is expected that having an older sibling will be related to positive friendship quality.

\subsubsection{Gender composition.}

For non-PI children, same-gender siblings may be more beneficial than opposite-gender siblings. Same-gender siblings report higher levels of positivity (females only; Buhrmester \& Furman, 1990), warmth and closeness (Furman \& Buhrmester, 1985a), companionship (Furman \& Buhrmester, 1985b), and intimacy (Furman \& Buhrmester, 1985b) than opposite-gender siblings. In fact, Furman and Buhrmester (1985b) described same-sex sibling relationships as friendships, but with higher levels of conflict. The positive effects of same-gender sibling dyads may also be associated with friendship quality (see above), although the association with maternal relationship quality is unclear. 


\subsubsection{Adoption status of sibling.}

The benefits of a sibling who is a biological child of the adoptive parents vs. an adoptee are unknown. For international adoptees (PI and non-PI), having more biological children in the adoptive family was associated with more behavior problems among adoptees, but not for those adopted with a biological sibling (Boer et al., 1994). Those adopted with biological siblings also had fewer problems than single adoptees, regardless of adoptive siblings (Boer et al., 1994; Erich \& Leung, 2002). Conversely, biological children, who have not experienced institutional neglect, may be better models for appropriate relationship behaviors than other PI children.

\subsection{THE CURRENT STUDY}

The current study represented the first inquiry of PI children's self-reported relationship quality with mothers, siblings, and best same-sex friends. Children aged 10-17 years who had been adopted from primarily social-emotionally depriving Baby Homes in the Russian Federation completed a self-report relationship quality questionnaire to investigate the following questions:

1. What is the nature of the pattern of important relationships in PI children, and does this pattern differ from that of non-PI children? It was expected that PI children's pattern of relationships with mother, sibling, and best friend would be similar to that of non-PI children, but that PI children would report poorer relationship quality.

2. Does more prolonged social-emotional deprivation early in life relate to the quality of important relationships during later childhood and adolescence? Children adopted at older ages were expected to have poorer quality relationships with mother, sibling, and best friend (Le Mare 
et al., 2001). Attachment theory and past research on s ocial skills (Julian, 2011) and behavior problems (Hawk \& McCall, in press) with this sample suggest relationship quality might be poorer in children adopted after $18 \mathrm{~m}$ onths of age, but relationship quality could continue to decrease with accumulated experience in the depriving institution (Sroufe et al., 1999).

3. Do sibling relationship characteristics moderate the association between age at adoption and relationship quality? Children with older siblings and those in same-sex sibling dyads were expected to show a s maller age-at-adoption effect than those with younger and opposite-sex siblings, respectively (Buhrmester \& Furman, 1990; Furman \& Buhrmester, 1985a). Predictions could not be made about sibling adoption status. 


\subsection{METHODS AND EXPERIMENTAL DESIGN}

\subsection{PARTICIPANTS}

Participants were 91 children between the ages of 10 and 17 years $(M=13.98, S D=2.27)$ who were adopted from institutions in the Russian Federation into USA families. The Russian institutions have selective social-emotional deficiencies but adequate physical resources (see above; The St. Petersburg-USA Orphanage Research Team, 2005, 2 008). Because of this distinction, outcomes for these children can more specifically be attributed to early socialemotional deprivation.

\subsection{PROCEDURE}

Parents and children were made aware of the study through an article in the adoption agency's newsletter. They then received the packet of questionnaires containing a letter from the adoption agency director and informed consent materials. Some questionnaires were child self-report, and a separate informed assent for the child was included. Specific instructions were given for the parents not to look at the children's answers, and for the children to complete the questionnaire in private and to seal it for privacy. Participants were offered a modest payment (\$15) for completion of the surveys (child response rate $=22 \%$ ). 


\subsubsection{Demographic information.}

Parents (78\% mothers) reported the child's date of birth, date of adoption, and date of testing, which were used to calculate age at adoption and age at assessment. They also reported the child's gender, and the age, gender, and adoption status of all siblings. Children indicated their own age and gender, whether they had a sibling, the age and gender of their sibling, and whether they had a b est friend. Information was crosschecked between informants to ensure accurate data; no discrepancies were found. Because many parents did not report family demographic data, such as family income and parent's education $(n=27)$ or pre-adoptive child factors, such as birth weight $(n=71)$, they were not used as covariates in the analyses.

Age at adoption was used as a surrogate for time in the institution $(r=.69$ using Baby Home records; Hawk \& McCall, 2011). In previous analyses with this sample, rates of parentreported behavior problems, social skills, and executive functioning were minimal before but much higher after 18 months at adoption (Hawk \& McCall, 2010; Julian, 2010; Merz \& McCall, in press). Thus, age at adoption is used both as a continuous $(\mathrm{M}=13.21, \mathrm{SD}=9.13)$ and a categorical (0-17 months: $n=71 ; 18-48$ months: $n=20)$ variable in the current analyses.

Due to the small sample size, characteristics of the sibling relationship were divided into three groups. Sibling relative age was defined as no sibling $(n=27)$, older sibling $(n=25$; mean age difference $=5.91, \mathrm{SD}=6.39)$, or younger sibling $(n=36$; mean age difference $=3.22, \mathrm{SD}=$ 2.31). Gender composition was defined as no sibling $(n=27)$, same gender (i.e., both boys or both girls; $n=26)$, or opposite gender $(n=36)$. Finally, sibling adoption status was defined as no sibling $(n=27)$, biological child of adoptive parents $(n=19)$, or adopted child $(n=35)$. Only four children had a genetically related sibling; therefore, the adopted child category included siblings both genetically related and unrelated to the focal child. 


\subsubsection{Network of Relationships Inventory: Social Provisions Version.}

The Network of Relationships Inventory: Social Provisions Version (NRI: SPV; Furman \& Buhrmester, 1985b) is a child self-report questionnaire that addresses relationship quality with significant others. It has previously been used to assess relationships with parents, grandparents, siblings, friends, teachers, and romantic partners, and has been given to children in $3^{\text {rd }}$ grade through college (Furman \& Buhrmester, 1985b; Furman \& Buhrmester, 1992). For the current study, children were asked to answer questions based on relationships with their mother, samesex best friend, and sibling. These nominations were self-selected, and if children had more than one best friend or sibling, they were asked to select the one who is most important to them. They could also indicate that they had no best friend $(n=3)$ or no sibling $(n=27)$.

The NRI: SPV contains 42 questions reflecting the extent to which certain characteristics are indicative of the relationship (e.g., How much does this person really care about you?), which are answered in a Likert format ranging from 1 (little or none) to 5 (the most) for all but the Relative Power items, in which anchors refer to the person with more power $(1=$ they almost always do to $5=$ I almost always do). Items are answered separately for each relationship.

The items form 14 subscales, each derived from averaging three questions. The composite index of Social Support consists of the average of the subscales of Companionship, Instrumental Aid, Intimacy, Nurturance, Affection, Admiration, Reliable Alliance, Satisfaction, and Support. Higher scores on these scales reflect better relationship quality. The Negative Interaction composite index consists of the average of the subscales Conflict, Antagonism, Criticism, and Dominance1. Higher scores on these scales reflect poorer relationship quality.

1 Confirmatory factor analyses supported the use of these two composites. 
Relative Power was not included in analyses because is not included in either of the broader indexes. Although the NRI: SPV is a self-report measure that shows the children's subjective interpretation of the relationship, rather than its objective quality, the children's perception may be the most important aspect of the relationships because this shapes their own behaviors and their interpretation of others' behaviors (Furman, 1996).

The NRI: SPV had adequate reliability in the current sample; Cronbach's alpha internal consistencies for all subscale scores were greater than $.60(\mathrm{M}=.78)$, except mother instrumental aid (.30). The composite scores had Cronbach's alphas between .85 (best friend negative interaction) and .94 (best friend social support). Validity had been examined by comparing scores across informants, with correlations of .34 for Support and .63 for Negative Interactions for scores between best friends (Furman, 1996).

In the current sample, validity of the NRI was investigated by comparing composite scores to the parent-reported Internalizing and Externalizing broadband scales of the Child Behavior Checklist (CBCL, Achenbach \& Rescorla, 2001). Using both extreme CBCL scores (T $>61)$ and mean scores, high Internalizing and Externalizing scores were associated with lower Social Support and higher Negative Interaction scores; however, these associations were only significant for mothers (Internalizing and Externalizing; most $p<.10$ ) and siblings (Internalizing only; all $p<.09$ ). Thus, poorer self-reported relationship quality did appear consistent with parent-reported behaviors. 


\subsection{SELECTIVE RESPONDING}

To determine whether the current sample, which consisted only of children whose parents allowed them to complete the surveys, was selective, CBCL behavior problem scores were compared between children with self-report and parent-report data $(n=83)$ and children of the same age (10-17) with only parent-report data $(n=63)$. A multivariate analysis of variance (MANOVA) comparing the two groups on CBCL Internalizing, Externalizing, Social, Thought, and Attention problems was not significant, $F(5,128)=1.39, p=.23$, nor were any univariate tests (all $p>.10)$. Thus, it appears that the sample was not selective by parents or children for problem behavior. 


\subsection{RESULTS}

\subsection{RELATIONSHIP QUALITY IN THE FULL SAMPLE}

It is possible that a relationship quality measure created for non-PI children may not be appropriate for PI children. To address this concern, the subscale scores for each relationship (within-subject) and their association with age at assessment (dichotomized 10-13 and 14-17) and gender (both between-subject) were examined in individual repeated measures analyses of variance (ANOVA) with post hoc comparisons between relationship sources. These analyses included only children with data for all three relationships $(n=64)$. Mean scores for each subscale for the current PI sample and a non-PI sample of Lempers and Clarklempers (1992) are

presented in Table 1, and score profiles of PI children are presented in Figure 1. The relationship quality among sources, described below, was similar to those found in the non-PI literature, supporting the appropriateness of the NRI for PI children. 
Table 1. Mean (Standard Deviation) Relationship Quality Subscale Scores for each Relationship Type for PI and non-PI (Lempers \& Clarklempers, 1992) Children

\begin{tabular}{|c|c|c|c|c|c|c|}
\hline & Mother & Mother & Sibling & Sibling & Friend & Friend \\
\hline & PI & Non-PI & PI & Non-PI & PI & Non-PI \\
\hline & $n=91$ & $n=799$ & $n=64$ & $n=799$ & $n=86$ & $n=799$ \\
\hline & 3.93 & & 3.25 & & 3.81 & \\
\hline Social Support & $(0.55)$ & & $(0.82)$ & & $(0.74)$ & \\
\hline & 3.52 & $3.17^{\mathrm{b}}$ & 3.22 & 3.26 & 3.65 & $3.99^{\mathrm{b}}$ \\
\hline Companionship $^{a}$ & $(1.01)$ & $(0.81)$ & $(1.13)$ & $(0.86)$ & $(0.87)$ & $(0.77)$ \\
\hline & 3.00 & 2.92 & 2.30 & $2.77^{b}$ & 3.15 & 3.27 \\
\hline Instrumental $\mathrm{Aid}^{\mathrm{c}}$ & $(0.75)$ & $(0.86)$ & $(0.98)$ & $(0.96)$ & $(0.99)$ & $(0.85)$ \\
\hline & 2.87 & 2.76 & 2.08 & $2.72^{c}$ & 3.60 & 3.81 \\
\hline Intimacy $^{c}$ & $(1.18)$ & $(1.02)$ & $(1.16)$ & $(1.10)$ & $(1.16)$ & $(0.97)$ \\
\hline & 3.69 & $3.28^{\mathrm{c}}$ & 3.40 & 3.36 & 3.61 & 3.58 \\
\hline Nurturance & $(0.89)$ & $(0.91)$ & $(1.06)$ & $(0.93)$ & $(1.00)$ & $(0.89)$ \\
\hline & 4.84 & $4.30^{\mathrm{c}}$ & 4.04 & $3.71^{b}$ & 4.08 & $3.79^{\mathrm{a}}$ \\
\hline Affection $^{c}$ & $(0.38)$ & $(0.80)$ & $(1.07)$ & $(0.94)$ & $(0.83)$ & $(0.85)$ \\
\hline & 4.23 & $3.62^{c}$ & 3.31 & 3.26 & 4.00 & $3.75^{\mathrm{a}}$ \\
\hline Admiration $^{\mathrm{c}}$ & $(0.74)$ & $(0.85)$ & $(1.17)$ & $(0.96)$ & $(0.88)$ & $(0.84)$ \\
\hline & 4.76 & $4.22^{c}$ & 4.30 & $3.91^{b}$ & 4.22 & $3.87^{\mathrm{a}}$ \\
\hline Reliable Alliance $^{c}$ & $(0.53)$ & $(0.91)$ & $(0.90)$ & $(0.91)$ & $(0.86)$ & $(0.90)$ \\
\hline & 4.44 & $3.80^{c}$ & 3.90 & $3.60^{\mathrm{a}}$ & 4.39 & $4.00^{c}$ \\
\hline Satisfaction $^{c}$ & $(0.90)$ & $(0.95)$ & $(1.10)$ & $(0.91)$ & $(0.81)$ & $(0.82)$ \\
\hline
\end{tabular}




\begin{tabular}{|c|c|c|c|c|c|c|}
\hline & 4.01 & & 2.79 & & 3.63 & \\
\hline \multirow[t]{2}{*}{ Support ${ }^{\mathrm{c}}$} & $(0.97)$ & & $(1.16)$ & & $(1.16)$ & \\
\hline & 2.58 & & 2.80 & & 1.82 & \\
\hline \multirow[t]{2}{*}{ Negative Interaction ${ }^{\mathrm{c}}$} & $(0.76)$ & & $(0.87)$ & & $(0.62)$ & \\
\hline & 1.79 & & 2.28 & & 1.56 & \\
\hline \multirow[t]{2}{*}{ Criticism $^{\mathrm{c}}$} & $(0.97)$ & & $(1.14)$ & & $(0.74)$ & \\
\hline & 2.52 & 2.50 & 2.99 & $2.74^{\mathrm{a}}$ & 1.70 & $1.98^{\mathrm{b}}$ \\
\hline \multirow[t]{2}{*}{ Conflict $^{\mathrm{c}}$} & $(0.96)$ & $(0.79)$ & $(1.08)$ & $(0.97)$ & $(0.71)$ & $(0.75)$ \\
\hline & 2.66 & & 3.39 & & 1.83 & \\
\hline \multirow[t]{2}{*}{ Antagonism $^{\mathrm{c}}$} & $(1.03)$ & & $(1.13)$ & & $(0.87)$ & \\
\hline & 3.34 & & 2.56 & & 2.20 & \\
\hline Dominance $^{c}$ & $(1.00)$ & & $(0.99)$ & & $(0.78)$ & \\
\hline
\end{tabular}

Note. For Social Support subscales, high scores mean better relationship quality; however, for Negative Interaction subscales, high scores mean poorer relationship quality. In comparisons between relationships for PI children only, significance is indicated in first column; analyses included only children with data for all three relationships. In comparisons between PI and Non-PI (Lempers \& Clarklempers, 1992) children for each relationship, significance is indicated in non-PI relationship column; analyses included all children with data for each relationship.

$$
{ }^{\mathrm{a}} p<.05 .{ }^{\mathrm{b}} p<.01 .{ }^{\mathrm{c}} p<.001 \text {. }
$$




\subsubsection{Comparisons between relationships (main effects).}

Relative to the other referents, PI children rated their mothers as the highest source of overall Social Support, $F(2,130)=15.461, p<.001$, including the subscales of Affection, $F(2,130)=$ 22.366, $p<.001$, Admiration, $F(2,130)=22.835, p<.001$, Satisfaction, $F(2,130)=6.826, p=$ .002 , Support, $F(2,130)=24.464, p<.001$, and Reliable Alliance, $F(2,130)=9.574, p<.001$. Mothers were also rated highest in Dominance, $F(2,130)=34.506, p<.001$. Friends were highest for Companionship, $F(2,130)=3.412, p=.04$, Instrumental Aid, $F(2,130)=15.264, p$ $<.001$, a nd Intimacy, $F(2,130)=22.097, p<.001$. Sibling relationships contained the most overall Negative Interactions, $F(2,130)=41.004, p<.001$, including Criticism, $F(2,130)=$ 12.504, $p<.001$, Conflict, $F(2,130)=39.395, p<.001$, and Antagonism, $F(2,130)=44.974, p$ $<.001$ (see Table 1 and Figure 1). 


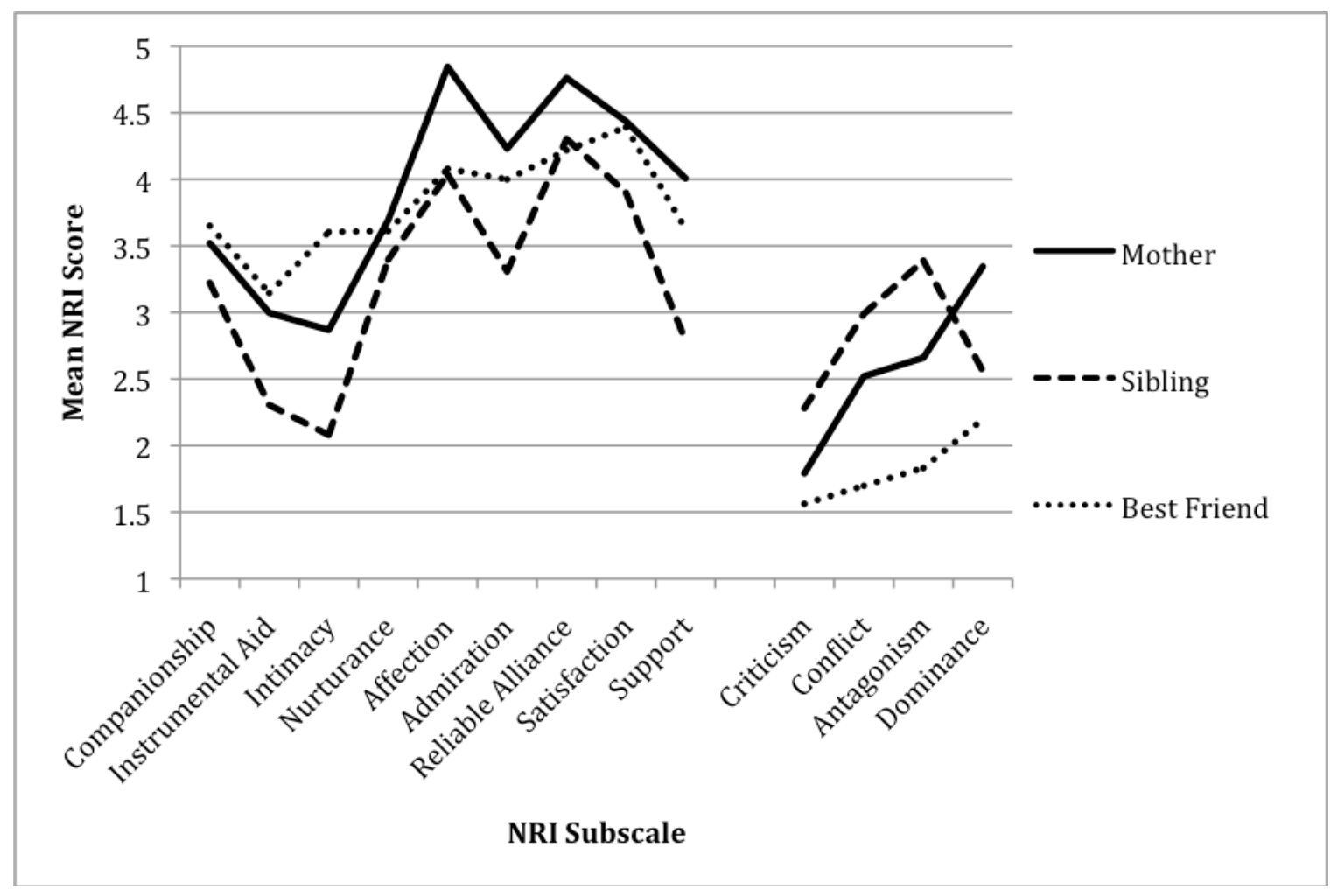

Figure 1. Relationship quality profiles for PI children's mothers, siblings, and best friends. For positive quality subscales, higher scores indicate better quality (left). For negative quality subscales, higher scores indicate poorer quality (right).

\subsubsection{Non-PI versus PI.}

Table 1 shows comparisons between the current PI sample and a sample of predominantly white, 11-19-year-old children reared by their biological parents in working-class or middle-class families in rural midwestern towns (Lempers \& Clarklempers, 1992). Similar to the current findings, the non-PI children indicated that mothers were highest for Affection and Reliable Alliance; friends were highest for Companionship, Instrumental Aid, and Intimacy; and siblings were highest for conflict. They differed for Admiration and Satisfaction, in which the PI children rated the mother as highest, but non-PI children rated friends as highest. 
Post-hoc t-tests, however, show that PI children tended to report better relationship quality than non-PI children. For mothers, PI children reported higher Companionship, $t(888)=$ $3.80, p=.001, \mathrm{~N}$ urturance, $t(888)=4.08, p<.001$, A ffection, $t(888)=6.36, p<.001$, Admiration, $t(888)=6.57, p<.001$, Reliable Alliance, $t(888)=5.55, p<.001$, and Satisfaction, $t(888)=6.12, p<.001$. For siblings, PI children reported higher Affection, $t(861)=2.67, p=$ .001 , Reliable Alliance, $t(861)=3.30, p=.001$, Satisfaction, $t(861)=2.50, p=.02$, and Conflict, $t(861)=1.97, p=.05$. Conversely, they reported lower Instrumental Aid, $t(861)=2.76, p=.001$, and Intimacy, $t(861)=5.05, p<.001$, with siblings. For friends, PI children reported higher Affection, $t(883)=3.01, p=.01$, Admiration, $t(883)=2.61, p=.01$, Reliable Alliance, $t(883)=$ .01 , Satisfaction, $t(883)=4.12, p<.001$. C onversely, Companionship, $t(883)=.001$, a nd Conflict, $t(883)=3.32, p=.001$, were lower for PI than non-PI children (see Table 1).

\subsubsection{Age at assessment and gender.}

Research with non-PI children suggests that as children grow from middle childhood through adolescence, their perceived social support from mothers and siblings decreases, while their social support from friends increases. Conflict is highest in the sibling relationship, and conflict tends to increase with age for mother relationships but decrease in friendships. Girls also tend to report higher relationship quality scores than boys (Buhrmester \& Furman, 1990; Furman \& Buhrmester, 1992). To investigate age at assessment and gender effects (between-subject) and their interactions with relationship source (within-subject) in the current sample, repeated measures ANOVAs were calculated with post-hoc contrasts for relationship source interactions.

Significant relationship type $\mathrm{X}$ age at assessment interactions suggest that Social Support, $F(2,58)=4.68, p=.01$, including Companionship $(F(2,57)=7.04, p=.002$, Instrumental Aid, 
$F(2,58)=4.44, p=.02$, Intimacy, $F(2,57)=11.80, p<.001$, and Support, $F(2,57)=3.84, p=$ .03 , from mothers and siblings is lower in older than younger children, while it remains at the same level within friendships. No significant age-at-assessment effects were found in Negative Interaction subscales (see Table 2).

Table 2. Mean (Standard Deviation) Relationship Quality by Relationship Source and Age at Assessment

\begin{tabular}{|c|c|c|c|c|c|c|}
\hline & & & & & & \\
\hline & $10-13$ & $14-17$ & $10-13$ & $14-17$ & $10-13$ & $14-17$ \\
\hline & Years & Years & Years & Years & Years & Years \\
\hline & $n=31$ & $n=32$ & $n=31$ & $n=32$ & $n=31$ & $n=32$ \\
\hline & 4.18 & 3.58 & 3.56 & 3.01 & 3.70 & 3.82 \\
\hline Social Support & $(0.40)$ & $(0.59)$ & $(0.68)$ & $(0.83)$ & $(0.67)$ & $(0.86)$ \\
\hline & 4.00 & 2.89 & 3.56 & 2.96 & 3.65 & 3.71 \\
\hline Companionship & $(0.70)$ & $(1.05)$ & $(1.06)$ & $(1.07)$ & $(0.87)$ & $(0.91)$ \\
\hline & 3.00 & 2.97 & 2.66 & 2.00 & 2.96 & 3.29 \\
\hline Instrumental Aid & $(0.60)$ & $(0.80)$ & $(0.92)$ & $(0.93)$ & $(0.86)$ & $(1.24)$ \\
\hline & 3.43 & 2.15 & 2.39 & 1.81 & 3.10 & 3.90 \\
\hline Intimacy & $(1.16)$ & $(0.98)$ & $(1.24)$ & $(1.01)$ & $(1.08)$ & (1.19) \\
\hline & 3.82 & 3.38 & 3.65 & 3.13 & 3.50 & 3.57 \\
\hline Nurturance & $(0.80)$ & $(1.05)$ & $(0.99)$ & $(1.10)$ & $(0.95)$ & (1.13) \\
\hline & 4.90 & 4.74 & 4.33 & 3.84 & 4.13 & 3.93 \\
\hline Affection & $(0.37)$ & $(0.45)$ & $(0.86)$ & $(1.09)$ & $(0.74)$ & $(0.93)$ \\
\hline Admiration & 4.42 & 3.92 & 3.69 & 3.00 & 3.95 & 3.96 \\
\hline
\end{tabular}




\begin{tabular}{|c|c|c|c|c|c|c|}
\hline & $(0.61)$ & $(0.79)$ & $(1.05)$ & $(1.14)$ & $(0.88)$ & $(0.93)$ \\
\hline & 4.84 & 4.61 & 4.44 & 4.25 & 4.20 & 4.16 \\
\hline \multirow[t]{2}{*}{ Reliable Alliance } & $(0.31)$ & $(0.78)$ & $(0.61)$ & $(1.04)$ & $(0.77)$ & $(0.98)$ \\
\hline & 4.70 & 3.94 & 4.17 & 3.65 & 4.42 & 4.25 \\
\hline \multirow[t]{2}{*}{ Satisfaction } & $(0.43)$ & $(1.22)$ & $(0.86)$ & $(1.28)$ & $(0.75)$ & $(0.89)$ \\
\hline & 4.46 & 3.58 & 2.11 & 2.50 & 3.42 & 3.65 \\
\hline \multirow{2}{*}{ Support } & $(0.64)$ & $(1.06)$ & $(1.08)$ & $(1.18)$ & $(1.24)$ & $(1.16)$ \\
\hline & 2.49 & 2.78 & 2.69 & 2.87 & 1.88 & 1.78 \\
\hline \multirow[t]{2}{*}{ Negative Interaction } & $(0.60)$ & $(0.88)$ & $(0.78)$ & $(0.91)$ & $(0.71)$ & $(0.57)$ \\
\hline & 1.59 & 2.08 & 2.23 & 2.28 & 1.62 & 1.53 \\
\hline \multirow[t]{2}{*}{ Criticism } & $(0.76)$ & $(1.17)$ & $(1.01)$ & $(1.24)$ & $(0.69)$ & $(0.82)$ \\
\hline & 2.51 & 2.84 & 2.84 & 3.08 & 1.76 & 1.65 \\
\hline \multirow[t]{2}{*}{ Conflict } & $(0.82)$ & $(1.14)$ & $(1.06)$ & $(1.06)$ & $(0.80)$ & $(0.67)$ \\
\hline & 2.50 & 2.84 & 3.19 & 3.53 & 1.92 & 1.75 \\
\hline \multirow[t]{2}{*}{ Antagonism } & $(0.85)$ & $(1.14)$ & $(1.09)$ & $(1.15)$ & $(0.98)$ & $(0.73)$ \\
\hline & 3.35 & 3.33 & 2.50 & 2.58 & 2.19 & 2.19 \\
\hline Dominance & $(3.33)$ & $(1.17)$ & $(0.85)$ & $(1.12)$ & $(0.80)$ & $(0.75)$ \\
\hline
\end{tabular}

Gender X relationship type interactions revealed that for Social Support, $F(2,58)=4.67$, $p=.01$, including Companionship, $F(2,57)=3.46, p=.04$, Intimacy, $F(2,57)=3.35, p=.04$, Affection, $F(2,57)=8.00, p=.001$, Admiration, $F(2,57)=4.29, p=.02$, Reliable Alliance, $F(2$, $57)=6.49, p=.003$, a nd Support, $F(2,57)=5.86, p=.005$, g irls reported higher quality 
friendships than boys, but no di fferences or slightly lower quality in mother and sibling relationships. Girls also reported more Conflict, $F(2,57)=5.49, p=.007$, with mothers than boys (see Table 3). The three-way interactions were not significant.

Table 3. Mean (Standard Deviation) Relationship Quality by Relationship Source and Gender.

\begin{tabular}{|c|c|c|c|c|c|c|}
\hline & & & & & & \\
\hline & Male & Female & Male & Female & Male & Female \\
\hline & $n=30$ & $n=33$ & $n=30$ & $n=33$ & $n=30$ & $n=33$ \\
\hline & 3.94 & 3.80 & 3.30 & 3.26 & 3.48 & 4.02 \\
\hline Social Support & $(0.50)$ & $(0.65)$ & $(0.74)$ & $(0.86)$ & $(0.84)$ & $(0.60)$ \\
\hline & 3.43 & 3.43 & 3.49 & 3.04 & 3.53 & 3.82 \\
\hline Companionship & $(1.03)$ & $(1.08)$ & $(0.99)$ & $(1.16)$ & $(0.96)$ & $(0.80)$ \\
\hline & 2.86 & 3.10 & 2.30 & 2.35 & 3.00 & 3.25 \\
\hline Instrumental Aid & $(0.58)$ & $(0.80)$ & $(1.00)$ & $(0.97)$ & $(1.03)$ & $(1.11)$ \\
\hline & 3.01 & 2.57 & 2.10 & 2.09 & 3.04 & 3.92 \\
\hline Intimacy & $(1.16)$ & $(1.30)$ & $(1.01)$ & $(1.30)$ & $(1.24)$ & $(1.00)$ \\
\hline & 3.63 & 3.56 & 3.55 & 3.24 & 3.26 & 3.79 \\
\hline Nurturance & $(0.92)$ & $(1.00)$ & $(0.89)$ & $(1.21)$ & $(1.17)$ & $(0.83)$ \\
\hline & 4.87 & 4.78 & 4.06 & 4.11 & 3.66 & 4.37 \\
\hline Affection & $(0.41)$ & $(0.43)$ & $(0.90)$ & $(1.11)$ & $(0.85)$ & $(0.70)$ \\
\hline & 4.22 & 4.11 & 3.22 & 3.46 & 3.66 & 4.22 \\
\hline Admiration & $(0.72)$ & $(0.78)$ & $(0.98)$ & $(1.28)$ & $(1.02)$ & $(0.68)$ \\
\hline & 4.84 & 4.62 & 4.28 & 4.40 & 3.95 & 4.38 \\
\hline Reliable Alliance & $(0.30)$ & $(0.77)$ & $(0.87)$ & $(0.84)$ & $(0.97)$ & $(0.73)$ \\
\hline
\end{tabular}




\begin{tabular}{|lcccccc|}
\hline \multirow{3}{*}{ Satisfaction } & 4.43 & 4.20 & 3.93 & 3.89 & 4.18 & 4.47 \\
& $(0.84)$ & $(1.11)$ & $(1.07)$ & $(1.17)$ & $(0.98)$ & $(0.63)$ \\
Support & 4.20 & 3.85 & 2.77 & 2.83 & 3.07 & 3.95 \\
Negative Interaction & $(0.84)$ & $(1.08)$ & $(1.11)$ & $(1.23)$ & $(1.21)$ & $(1.02)$ \\
& 2.48 & 2.77 & 2.79 & 2.77 & 1.81 & 1.84 \\
Criticism & $(0.53)$ & $(0.91)$ & $(0.79)$ & $(0.91)$ & $(0.67)$ & $(0.62)$ \\
& 1.57 & 2.09 & 2.20 & 2.30 & 1.50 & 1.64 \\
Conflict & $(0.70)$ & $(1.19)$ & $(1.07)$ & $(1.19)$ & $(0.73)$ & $(0.78)$ \\
& 2.30 & 3.02 & 3.02 & 2.90 & 1.70 & 1.71 \\
Antagonism & $(0.79)$ & $(1.06)$ & $(0.91)$ & $(1.19)$ & $(0.71)$ & $(0.76)$ \\
& 2.48 & 2.85 & 3.48 & 3.25 & 1.87 & 1.80 \\
& $(0.86)$ & $(1.12)$ & $(1.13)$ & $(1.12)$ & $(0.91)$ & $(0.83)$ \\
& 3.59 & 3.12 & 2.44 & 2.64 & 2.17 & 2.21 \\
& $(0.99)$ & $(1.04)$ & $(0.91)$ & $(1.06)$ & $(0.76)$ & $(0.79)$ \\
\hline
\end{tabular}

\subsection{AGE AT ADOPTION}

The primary variable of interest was age at adoption, because it had the possibility of reflecting the influence of the institutional experience. Because age-at-assessment and gender effects were seen in the sample, these variables were included in the following analyses as covariates and possible moderators and, as such, are reported only if they qualify age-at-adoption effects. To investigate the association between age at adoption and relationship quality, regression analyses 
were performed separately for each relationship source predicting the NRI composite scores with gender, age at assessment, age at adoption, and their interactions. Composite scores were used rather than subscale scores to decrease the total number of analyses and because the subscale scores included only three items each. Variables were entered in blocks to determine explained variance; however, tables report only the final model for clarity. Blocks were entered as follows: 1) Gender, 2) Age at Assessment, 3) Age at Adoption, 4) Gender $X$ Age at Assessment, 5) Gender X Age at Adoption, 6) Age at Adoption X Age at Assessment.

\subsubsection{Form of age at adoption.}

The first analyses addressed the form of the age at adoption function. Three competing models were tested: a linear model, a dichotomous model (cut-off $=18$ months), and a spline regression model (knot = 18 months; testing whether the slope of the regression line jumps or changes at 18 months). The only significant age-at-adoption effect for any relationship, controlling for the other variables, was the interaction of the linear age at adoption variable and gender in the prediction of best friend Negative Interaction, $R^{2}$ change $=.09, F(1,77)=8.33, p=.005$. The overall regression was marginally significant, $F(6,78)=1.99, p=.08, R^{2}=.13$. For girls, older age at adoption was related to more Negative Interaction, but for boys, older age at adoption was related to less Negative Interaction (see Table 4 and Figure 2). Neither the dichotomous model, $F(6,79)=0.89, p=.51$, nor the spline regression model, $F(10,75)=1.33, p=.23$, were significant. Subsequent analyses used only the linear age-at-adoption variable, and figures depict this linear association 
Table 4. Regression Coefficients from Analyses Predicting Relationship Quality with Age at Adoption

\begin{tabular}{|c|c|c|c|c|c|c|}
\hline & & & & & Best & end \\
\hline & $\mathrm{B}(\mathrm{SE})$ & $\beta$ & $\mathrm{B}(\mathrm{SE})$ & $\beta$ & $\mathrm{B}(\mathrm{SE})$ & $\beta$ \\
\hline Social Support & & & $R^{2}=$ & & & \\
\hline & 3.90 & & 3.16 & & 3.54 & \\
\hline (Constant) & $(0.09)$ & & $(0.15)$ & & $(0.12)$ & \\
\hline & 0.05 & & 0.15 & & 0.52 & \\
\hline Gender & $(0.12)$ & 0.04 & $(0.20)$ & 0.09 & $(0.16)$ & $0.35^{\mathrm{b}}$ \\
\hline & -0.10 & & -0.17 & & 0.04 & \\
\hline Age at Assessment & $(0.04)$ & $-0.41^{\mathrm{a}}$ & $(0.07)$ & $-0.44^{\mathrm{a}}$ & $(0.05)$ & 0.11 \\
\hline & -0.01 & & -0.01 & & 0.02 & \\
\hline Age at Adoption & $(0.01)$ & -0.13 & $(0.01)$ & -0.14 & $(0.01)$ & 0.24 \\
\hline & 0.03 & & 0.07 & & -0.08 & \\
\hline Gender X Assess & $(0.05)$ & 0.10 & $(0.09)$ & 0.14 & $(0.07)$ & -0.18 \\
\hline & 0.01 & & 0.02 & & -0.03 & \\
\hline Adopt X Gender & $(0.01)$ & 0.14 & $(0.02)$ & 0.16 & $(0.02)$ & -0.22 \\
\hline & $<0.001$ & & -0.01 & & 0.004 & \\
\hline Adopt X Assess & $(0.003)$ & 0.01 & $(0.01)$ & -0.22 & $(0.004)$ & 0.12 \\
\hline Negative Interaction & & & & & & \\
\hline & 2.50 & & 2.90 & & 1.84 & \\
\hline (Constant) & $(0.12)$ & & $(0.16)$ & & $(0.10)$ & \\
\hline Gender & 0.15 & 0.10 & -0.08 & -0.04 & -0.02 & -0.02 \\
\hline
\end{tabular}




\begin{tabular}{|lccccccc|}
\hline & $(0.17)$ & & $(0.22)$ & & $(0.14)$ & \\
& 0.04 & & 0.12 & & $<0.001$ & \\
Age at Assessment & $(0.06)$ & 0.11 & $(0.08)$ & 0.30 & $(0.05)$ & 0.002 \\
& $<0.001$ & & 0.01 & & -0.02 & \\
Age at Adoption & $(0.01)$ & -0.01 & $(0.02)$ & 0.05 & $(0.01)$ & -0.31 \\
& 0.02 & & -0.20 & & 0.004 & \\
Gender X Assess & $(0.07)$ & 0.03 & $(0.11)$ & -0.35 & $(0.06)$ & 0.01 \\
& 0.01 & & 0.01 & & 0.05 & \\
Adopt X Gender & $(0.02)$ & 0.11 & $(0.03)$ & 0.05 & $(0.02)$ & $0.43^{\mathrm{b}}$ \\
& 0.004 & & 0.01 & & 0.002 & \\
Adopt X Assess & $(0.004)$ & 0.12 & $(0.01)$ & 0.21 & $(0.003)$ & 0.08 \\
\hline
\end{tabular}

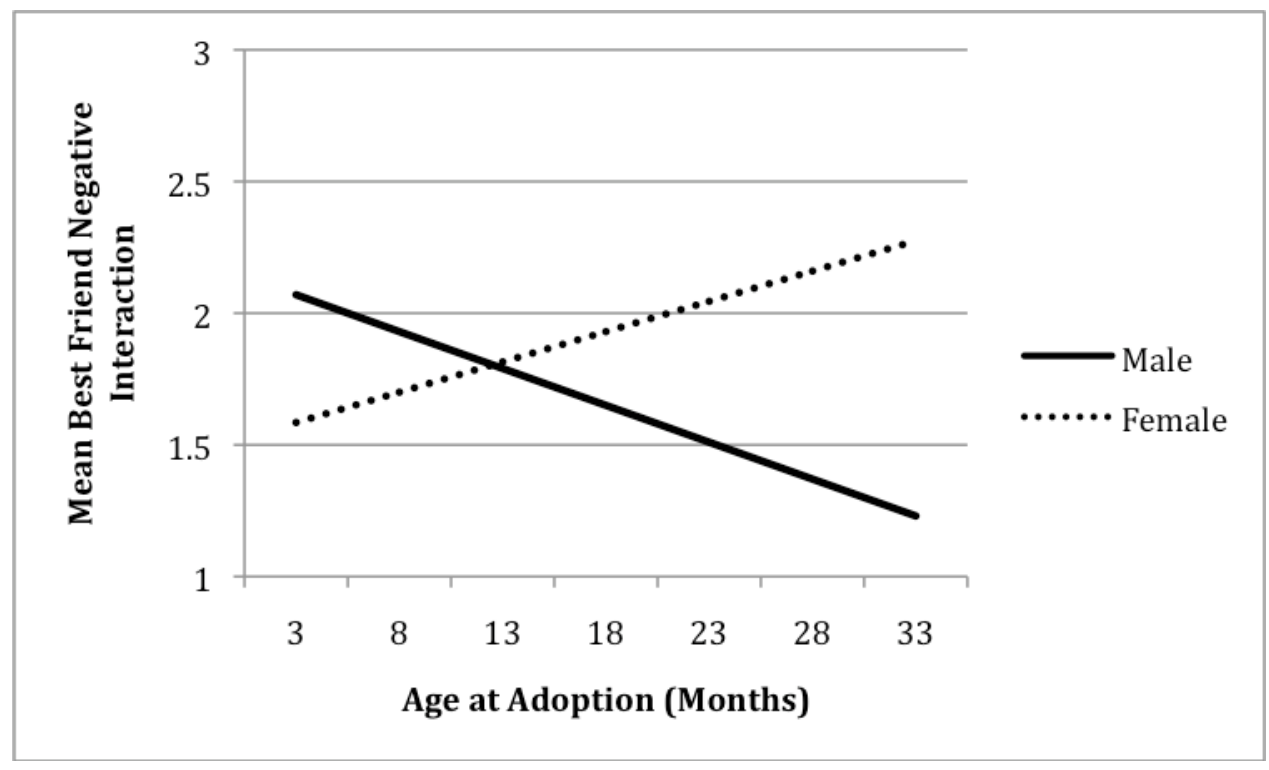

Figure 2. Linear interaction between age at adoption and gender for best friend Negative Interaction, controlling for age at assessment and the interaction of age at adoption and age at assessment. 


\subsection{EXTREME SCORES}

PI children are often distinguished by extremes rather than average scores (e.g., Hawk \& McCall, in press; Julian, 2010; Verhulst, et al., 1990), and extreme scores are more indicative of problematic behaviors rather than fluctuations within the normal range. Because no standardization sample exists that describes scores indicative of NRI "extreme problems" in nonPI children, "extreme good" and "extreme bad" scores were created in two ways using the current data. First, for Social Support, mean scores greater than 4 were considered "good" $(M=$ 4.45) and mean scores less than 2 were considered "bad" $(\mathrm{M}=1.46)$. For Negative Interaction, scores less than 2 w ere "good" $(M=1.56)$ and greater than 4 were "bad" $(M=4.60)$. This provided a description of the qualitatively highest and lowest scores. Second, z-scores were created, and, for Social Support, children with z-scores in the highest $15 \%$ were considered "good" $(M=2.47)$, whereas those in the lowest $15 \%$ were considered "bad" $(M=4.65)$. For Negative Interaction, the lowest $15 \%$ were "good" $(M=1.73)$ and the highest $15 \%$ were "bad" $(\mathrm{M}=3.72)$. The $15 \%$ cut-off is similar to the definition of "extreme problems" on the CBCL. Analyses revealed similar outcomes for both types of extreme scores; thus, only the qualitative score outcomes are reported. Table 5 presents the percentage of children with "good" and "bad" scores based on age at adoption, age at assessment, and gender, although the latter two are not discussed in text. Chi-squared analyses compared earlier vs. later adoptees, younger vs. older children, and boys vs. girls for each relationship quality score.

A higher percentage of later adoptees reported "good", $\chi^{2}=4.98, p=.03$, and "bad", $\chi^{2}$ $=5.28, p=.02$, Social Support from their siblings than earlier adoptees. Later adoptees also had a higher percentage of "bad" Negative Interaction, $\chi^{2}=4.98, p=.03$, with their siblings (see 
Table 5). Although age at adoption was dichotomized for simplicity, these percentages also increased linearly (e.g., percentage of children with extremely low sibling social support by age at adoption: $0-5$ months $=0 \% ; 6-11$ months $=3 \% ; 12-17$ months $=10 \% ; 18-23$ months $=20 \%$; 24-48 months $=25 \%$ ). Tests of age at adoption $\mathrm{X}$ age at assessment and age at adoption $\mathrm{X}$ gender revealed no significant effects.

Table 5. Percentage of Children with "Good" and "Bad" Extreme Relationship Quality Scores by Age at Adoption (Months), Age at Assessment (Years), and Gender

\begin{tabular}{|c|c|c|c|c|c|c|}
\hline & Age at & option & Age at $A$ & essment & & der \\
\hline & $0-17$ & $18-48$ & $10-13$ & $14-17$ & Male & Female \\
\hline Mother & $n=71$ & $n=20$ & $n=45$ & $n=46$ & $n=41$ & $n=50$ \\
\hline Social Support & & & & & & \\
\hline Good $(M>4)$ & $49 \%$ & $35 \%$ & $58 \%$ & $35 \%{ }^{\mathrm{a}}$ & $46 \%$ & $46 \%$ \\
\hline $\operatorname{Bad}(\mathrm{M}<2)$ & $1 \%$ & $0 \%$ & $0 \%$ & $2 \%$ & $0 \%$ & $2 \%$ \\
\hline Negative Interac & & & & & & \\
\hline Good $(\mathrm{M}<2)$ & $24 \%$ & $10 \%$ & $24 \%$ & $17 \%$ & $17 \%$ & $24 \%$ \\
\hline $\operatorname{Bad}(M>4)$ & $4 \%$ & $5 \%$ & $2 \%$ & $10 \%$ & $0 \%$ & $8 \%$ \\
\hline Sibling & $n=51$ & $n=13$ & $n=32$ & $n=31$ & $n=31$ & $n=33$ \\
\hline Social Support & & & & & & \\
\hline Good $(M>4)$ & $8 \%$ & $31 \%{ }^{\mathrm{a}}$ & $22 \%$ & $3 \%{ }^{a}$ & $10 \%$ & $15 \%$ \\
\hline $\operatorname{Bad}(\mathrm{M}<2)$ & $4 \%$ & $23 \%{ }^{\mathrm{a}}$ & $6 \%$ & $9 \%$ & $6 \%$ & $9 \%$ \\
\hline Negative Interac & & & & & & \\
\hline Good $(\mathrm{M}<2)$ & $16 \%$ & $17 \%$ & $16 \%$ & $16 \%$ & $16 \%$ & $16 \%$ \\
\hline
\end{tabular}




\begin{tabular}{|c|c|c|c|c|c|c|}
\hline $\operatorname{Bad}(\mathrm{M}>4)$ & $6 \%$ & $25 \%{ }^{\mathrm{a}}$ & $9 \%$ & $10 \%$ & $6 \%$ & $13 \%$ \\
\hline Best Friend & $n=69$ & $n=17$ & $n=42$ & $n=44$ & $n=38$ & $n=48$ \\
\hline \multicolumn{7}{|l|}{ Social Support } \\
\hline Good $(M>4)$ & $42 \%$ & $53 \%$ & $40 \%$ & $48 \%$ & $29 \%$ & $56 \%{ }^{\mathrm{a}}$ \\
\hline $\operatorname{Bad}(\mathrm{M}<2)$ & $1 \%$ & $0 \%$ & $0 \%$ & $2 \%$ & $3 \%$ & $0 \%$ \\
\hline \multicolumn{7}{|c|}{ Negative Interaction } \\
\hline Good $(\mathrm{M}<2)$ & $59 \%$ & $76 \%$ & $57 \%$ & $68 \%$ & $61 \%$ & $65 \%$ \\
\hline $\operatorname{Bad}(M>4)$ & $0 \%$ & $0 \%$ & $0 \%$ & $0 \%$ & $0 \%$ & $0 \%$ \\
\hline
\end{tabular}

Note. Comparisons are within variables (e.g., 0-17 vs. 18-48 months).

${ }^{\mathrm{a}} p<.05 .{ }^{\mathrm{b}} p<.01$.

\subsection{SIBLING CHARACTERISTICS}

The following analyses used linear regression to examine whether characteristics of siblings (relative age, gender composition, adoption status) were associated with relationship quality both directly and through interactions with age at adoption. Thus, main effects of sibling characteristics are reported if there is no age-at-adoption interaction. Variables were entered in blocks as follows: 1) Gender, 2) Sibling Characteristic, 3) Age at Assessment, 4) Age at Adoption, 5) Age at Assessment X Sibling Characteristic, 6) Age at Adoption X Sibling Characteristic. Tables show only the final model for simplicity. 


\subsubsection{Relative Age.}

Gender $(1$ = female), age at assessment, age at adoption, sibling relative age (older, younger, none; reference $=$ none , and interactions between sibling relative age, age at assessment and age adoption were used to predict mother, sibling, and friend Social Support and Negative Interaction (see Table 6). Results suggest a beneficial effect of having an older sibling, especially for later-adoptees.

Table 6. Regression Coefficients for Analyses Predicting Relationship Quality with Sibling Relative Age (No Sibling, Older Sibling, Younger Sibling)

\begin{tabular}{|c|c|c|c|c|c|c|}
\hline & Mol & & Sib & & Best I & nd \\
\hline & $\mathrm{B}(\mathrm{SE})$ & $\beta$ & $\mathrm{B}(\mathrm{SE})$ & $\beta$ & $\mathrm{B}(\mathrm{SE})$ & $\beta$ \\
\hline Social Support & $R^{2}=$ & & $R^{2}=$ & & $R^{2}=$ & \\
\hline & 4.02 & & 3.08 & & 3.52 & \\
\hline (Constant) & $(0.12)$ & & $(0.15)$ & & $(0.18)$ & \\
\hline & 0.02 & & 0.07 & & 0.65 & \\
\hline Female & $(0.11)$ & 0.02 & $(0.20)$ & 0.04 & $(0.17)$ & $0.44^{\mathrm{c}}$ \\
\hline & -0.04 & & 0.43 & & -0.15 & \\
\hline Older Sibling & $(0.14)$ & -0.03 & $(0.20)$ & $0.26^{\mathrm{a}}$ & $(0.20)$ & -0.09 \\
\hline & -0.21 & & & & 0.01 & \\
\hline Younger Sibling & $(0.13)$ & -0.19 & & & $(0.19)$ & 0.01 \\
\hline & $<0.001$ & & -0.14 & & -0.03 & \\
\hline Age at Assessment & $(0.04)$ & -0.01 & $(0.06)$ & $-0.38^{\mathrm{a}}$ & $(0.06)$ & -0.10 \\
\hline
\end{tabular}




\begin{tabular}{|c|c|c|c|c|c|c|}
\hline \multirow[b]{2}{*}{ Age at Adoption } & \multicolumn{2}{|l|}{-0.01} & \multicolumn{2}{|l|}{-0.01} & \multicolumn{2}{|l|}{-0.02} \\
\hline & $(0.01)$ & -0.22 & $(0.01)$ & -0.11 & $(0.02)$ & -0.26 \\
\hline & -0.12 & & 0.02 & & 0.01 & \\
\hline \multirow[t]{2}{*}{ Older X Asses } & $(0.06)$ & $-0.27^{\mathrm{a}}$ & $(0.09)$ & 0.04 & $(0.08)$ & 0.01 \\
\hline & -0.13 & & & & 0.09 & \\
\hline \multirow[t]{2}{*}{ Younger X Assess } & $(0.06)$ & $-0.30^{\mathrm{a}}$ & & & $(0.08)$ & 0.15 \\
\hline & 0.04 & & 0.05 & & & \\
\hline \multirow[t]{2}{*}{ Older X Adopt } & $(0.02)$ & $0.32^{\mathrm{a}}$ & $(0.02)$ & $0.33^{\mathrm{a}}$ & 0.05 & $0.33^{\mathrm{a}}$ \\
\hline & $<0.001$ & & & & & \\
\hline Younger X Adopt & $(0.01)$ & -0.02 & & & 0.02 & 0.20 \\
\hline \multirow[t]{2}{*}{ Negative Interaction } & \multicolumn{2}{|c|}{$R^{2}=.10$} & \multicolumn{2}{|c|}{$R^{2}=.09$} & \multicolumn{2}{|c|}{$R^{2}=.15$} \\
\hline & 2.43 & & 2.98 & & 2.05 & \\
\hline \multirow[t]{2}{*}{ (Constant) } & $(0.18)$ & & $(0.17)$ & & $(0.16)$ & \\
\hline & 0.16 & & 0.06 & & -0.24 & \\
\hline \multirow[t]{2}{*}{ Female } & $(0.18)$ & 0.11 & $(0.24)$ & 0.03 & $(0.15)$ & -0.19 \\
\hline & -0.15 & & -0.53 & & -0.09 & \\
\hline \multirow[t]{2}{*}{ Older Sibling } & $(0.21)$ & -0.09 & $(0.24)$ & $-0.30^{\mathrm{a}}$ & $(0.17)$ & -0.06 \\
\hline & 0.20 & & & & -0.24 & \\
\hline \multirow[t]{2}{*}{ Younger Sibling } & $(0.20)$ & 0.13 & & & $(0.17)$ & -0.19 \\
\hline & 0.06 & & 0.04 & & 0.03 & \\
\hline Age at Assessment & $(0.06)$ & 0.17 & $(0.07)$ & 0.11 & $(0.05)$ & 0.11 \\
\hline Age at Adoption & 0.03 & 0.32 & 0.00 & 0.01 & 0.03 & $0.49^{\mathrm{a}}$ \\
\hline
\end{tabular}




\begin{tabular}{|lcccccc|}
\hline & $(0.02)$ & & $(0.01)$ & & $(0.02)$ & \\
& -0.01 & & -0.04 & 0.02 & \\
Older X Asses & $(0.09)$ & -0.01 & $(0.11)$ & -0.07 & $(0.07)$ & 0.05 \\
& $<0.001$ & & & & -0.09 & \\
Younger X Assess & $(0.09)$ & -0.01 & & & $(0.07)$ & -0.18 \\
& -0.04 & & -0.02 & & -0.04 & \\
Older X Adopt & $(0.02)$ & -0.26 & $(0.03)$ & -0.09 & $(0.02)$ & $-0.32^{\mathrm{a}}$ \\
& -0.03 & & & & -0.06 & \\
Younger X Adopt & $(0.02)$ & -0.24 & & & $(0.02)$ & $-0.56^{\mathrm{b}}$ \\
\hline
\end{tabular}

Note. Analyses predicting sibling relationship quality included only the dummy variable indicating older siblings.

${ }^{\mathrm{a}} p<.05 .{ }^{\mathrm{b}} p<.01 .{ }^{\mathrm{c}} p<.001$.

\subsubsection{Mother.}

The overall regression predicting Social Support was significant, $F(9,81)=3.45, p=.001, R^{2}=$ .28. The $R^{2}$ change was significant for the interaction of age at adoption and sibling relative age, $R^{2}=.08, F(2,81)=4.41, p=.02$. F or children with no siblings or younger siblings, age at adoption was not associated with Social Support; but for those with older siblings, older ages at adoption were associated with more mother Social Support, holding all else constant (see Table 6 and Figure 3). The overall regression for Negative Interaction was not significant, $F(9,81)=$ $1.05, p=.41, R^{2}=.10$. 


\subsubsection{Sibling.}

The overall regression predicting sibling Social Support was significant, $F(6,57)=3.38, p=$ $.002, R^{2}=.25$. B ecause only children with siblings were included in these analyses, sibling relative age was converted to a dichotomous variable (older $=1$ ). The change in $R^{2}$ was significant for the interaction of age at adoption and sibling relative age, $R^{2}$ change $=.08, F(1$, $57)=5.70, p=.02$. For children with younger siblings, age at adoption was not related to sibling Social Support; but for children with older siblings, older age at adoption was associated with more Social Support (see Table 6 and Figure 3). The overall regression for sibling Negative Interaction was not significant, $F(6,56)=0.91, p=.49, R^{2}=.09$; however, the $R^{2}$ change was significant for sibling relative age, $R^{2}$ change $=.08, F(1,60)=4.78, p=.03$. Children with older siblings reported less Negative Interaction than those with younger siblings, $t(56)=-2.25, p=$ .03 (see Table 6).

\subsubsection{Best Friend.}

The overall regression predicting friend Social Support was significant, $F(9,76)=2.27, p=.03$, $R^{2}=.21$. The interaction between age at adoption and sibling relative age, specifically older sibling, was significant; however, the $R^{2}$ change was not, $F(2,76)=2.49, p=.09$ (see Table 6). The overall regression predicting friend Negative Interaction was not significant, $F(9,76)=1.50$, $p=.17, R^{2}=.15$, but the $R^{2}$ change for the interaction between age at adoption and sibling relative age was significant, $R^{2}$ change $=.11, F(2,76)=4.68, p=.01$. F or children with no sibling, older age at adoption was associated with more friend Negative Interaction; however, for children with younger or older siblings older age at adoption was associated with less Negative Interaction (see Table 6 and Figure 3). 

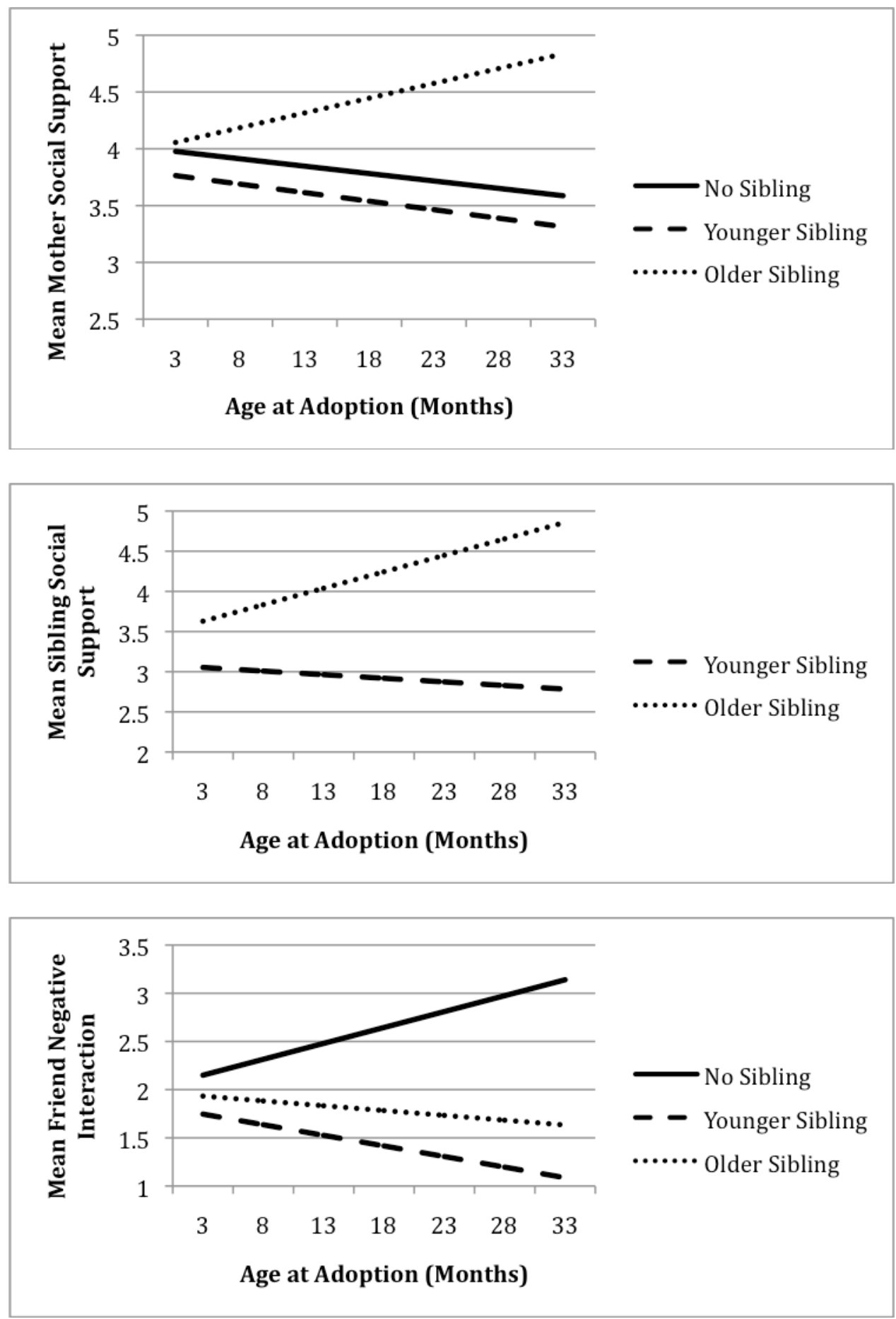

Figure 3. Linear interactions of age at adoption and sibling relative age for mother and sibling social support (higher $=$ better) and friend negative interaction (higher $=$ worse), controlling for age at assessment, gender, and interactions among the variables. 


\subsubsection{Sibling Adoption Status.}

Regression analyses were conducted predicting relationship quality with gender, age at assessment, age at adoption, and sibling adoption status (no sibling, biological child of adoptive parents, adopted child; reference $=$ no sibling $).$ Although the regressions predicting mother, $F(9$, $71)=2.29, p=.03, R^{2}=.23$, sibling, $F(6,49)=2.3, p=.049, R^{2}=.22$, and friend, $F(9,68)=$ 2.03, $p=.049, R^{2}=.21$, Social Support were significant, neither age at adoption nor sibling adoption status were significant predictors (see Table 7). The regressions predicting Negative Interaction were not significant for mother, $F(9,71)=0.98, p=.46$, sibling, $F(6,48)=0.38, p=$ .89 , or friend, $F(9,68)=0.72, p=.69($ see Table 7$)$.

Table 7. Regression Coefficients for Analyses Predicting Relationship Quality with Sibling Adoption Status (No Sibling, Biological Child, Adopted Child)

\begin{tabular}{|c|c|c|c|c|c|c|}
\hline & Mo & & $\mathrm{Sib}$ & & Best & \\
\hline & $\mathrm{B}(\mathrm{SE})$ & $\beta$ & $\mathrm{B}(\mathrm{SE})$ & $\beta$ & $\mathrm{B}(\mathrm{SE})$ & $\beta$ \\
\hline Social Support & $R^{2}=$ & & $R^{2}=$ & & $R^{2}=$ & \\
\hline & 4.00 & & 3.07 & & 3.52 & \\
\hline (Constant) & $(0.12)$ & & $(0.16)$ & & $(0.18)$ & \\
\hline & 0.05 & & 0.12 & & 0.61 & \\
\hline Female & $(0.12)$ & 0.05 & $(0.21)$ & 0.07 & $(0.17)$ & $0.40^{\mathrm{b}}$ \\
\hline & -0.22 & & 0.39 & & -0.02 & \\
\hline Biological & $(0.13)$ & -0.20 & $(0.22)$ & 0.23 & $(0.19)$ & -0.01 \\
\hline & 0.04 & & & & 0.06 & \\
\hline Adopted & $(0.15)$ & 0.03 & & & $(0.22)$ & 0.03 \\
\hline
\end{tabular}




\begin{tabular}{|c|c|c|c|c|c|c|}
\hline \multirow[b]{2}{*}{ Age at Assessment } & \multicolumn{2}{|l|}{-0.01} & \multicolumn{2}{|l|}{-0.15} & \multicolumn{2}{|l|}{-0.05} \\
\hline & $(0.04)$ & -0.04 & $(0.06)$ & $-0.39^{\mathrm{a}}$ & $(0.06)$ & -0.15 \\
\hline & -0.01 & & $<0.001$ & & -0.01 & \\
\hline \multirow[t]{2}{*}{ Age at Adoption } & $(0.01)$ & -0.13 & $(0.01)$ & -0.04 & $(0.02)$ & -0.12 \\
\hline & -0.09 & & 0.11 & & 0.01 & \\
\hline \multirow[t]{2}{*}{ Biological X Assess } & $(0.07)$ & -0.17 & $(0.10)$ & 0.17 & $(0.10)$ & 0.02 \\
\hline & -0.12 & & & & 0.10 & \\
\hline \multirow[t]{2}{*}{ Adopted X Assess } & $(0.06)$ & $-0.31^{\mathrm{b}}$ & & & $(0.08)$ & 0.19 \\
\hline & 0.03 & & 0.04 & & 0.04 & \\
\hline \multirow[t]{2}{*}{ Biological X Adopt } & $(0.02)$ & 0.23 & $(0.02)$ & 0.29 & $(0.03)$ & 0.26 \\
\hline & $<0.001$ & & & & 0.02 & \\
\hline Adopted X Adopt & $(0.02)$ & -0.03 & & & $(0.03)$ & 0.13 \\
\hline \multirow[t]{2}{*}{ Negative Interaction } & \multicolumn{2}{|c|}{$R^{2}=.11$} & \multicolumn{2}{|c|}{$R^{2}=.05$} & \multicolumn{2}{|c|}{$R^{2}=.09$} \\
\hline & 2.44 & & 3.04 & & 1.93 & \\
\hline \multirow[t]{2}{*}{ (Constant) } & $(0.19)$ & & $(0.19)$ & & $(0.17)$ & \\
\hline & 0.09 & & -0.18 & & -0.15 & \\
\hline \multirow[t]{2}{*}{ Female } & $(0.18)$ & 0.06 & $(0.24)$ & -0.11 & $(0.15)$ & -0.12 \\
\hline & 0.21 & & -0.24 & & -0.06 & \\
\hline \multirow[t]{2}{*}{ Biological } & $(0.20)$ & 0.14 & $(0.25)$ & -0.14 & $(0.18)$ & -0.05 \\
\hline & -0.09 & & & & $<0.001$ & \\
\hline Adopted & $(0.23)$ & -0.05 & & & $(0.20)$ & $<0.001$ \\
\hline Age at Assessment & 0.04 & 0.12 & 0.01 & 0.03 & 0.05 & 0.19 \\
\hline
\end{tabular}




\begin{tabular}{|lccccccc|}
\hline & $(0.06)$ & & $(0.07)$ & & $(0.05)$ & \\
Age at Adoption & 0.03 & & 0.01 & & 0.01 & \\
& $(0.02)$ & 0.37 & $(0.02)$ & 0.11 & $(0.02)$ & 0.18 \\
Biological X Asses & 0.04 & & -0.03 & & $<0.001$ & \\
& $(0.10)$ & 0.05 & $(0.12)$ & -0.04 & $(0.09)$ & $<0.001$ \\
Adopted X Assess & 0.02 & & & & -0.14 & \\
& $(0.09)$ & 0.03 & & & $(0.07)$ & -0.32 \\
Biological X Adopt & -0.04 & & -0.03 & & -0.02 & \\
& $(0.03)$ & -0.25 & $(0.03)$ & -0.19 & $(0.03)$ & -0.14 \\
Adopted X Adopt & -0.05 & & & & -0.01 & \\
& $(0.03)$ & -0.35 & & & $(0.02)$ & -0.13 \\
\hline
\end{tabular}

Note. Analyses predicting sibling relationship quality included only the dummy variable indicating siblings were biological children of the adoptive parents. ${ }^{\mathrm{a}} p<.05 .{ }^{\mathrm{b}} p<.01$.

\subsubsection{Gender Composition of Sibling Relationship.}

Regression equations were conducted predicting relationship quality with gender, age at assessment, age at adoption, and gender composition (none, same gender, or opposite gender; reference $=$ none $)$. Due to the small sample size, same-gender dyads could not be further divided into male $(n=9)$ vs. female $(n=17)$. Results suggest that older age at adoption is associated with poorer relationship quality with an opposite-gender sibling, but not with a same-gender sibling (see Table 8). 
Table 8. Regression Coefficients for Analyses Predicting Relationship Quality with Sibling Gender Composition (No Sibling, Opposite Gender, Same Gender)

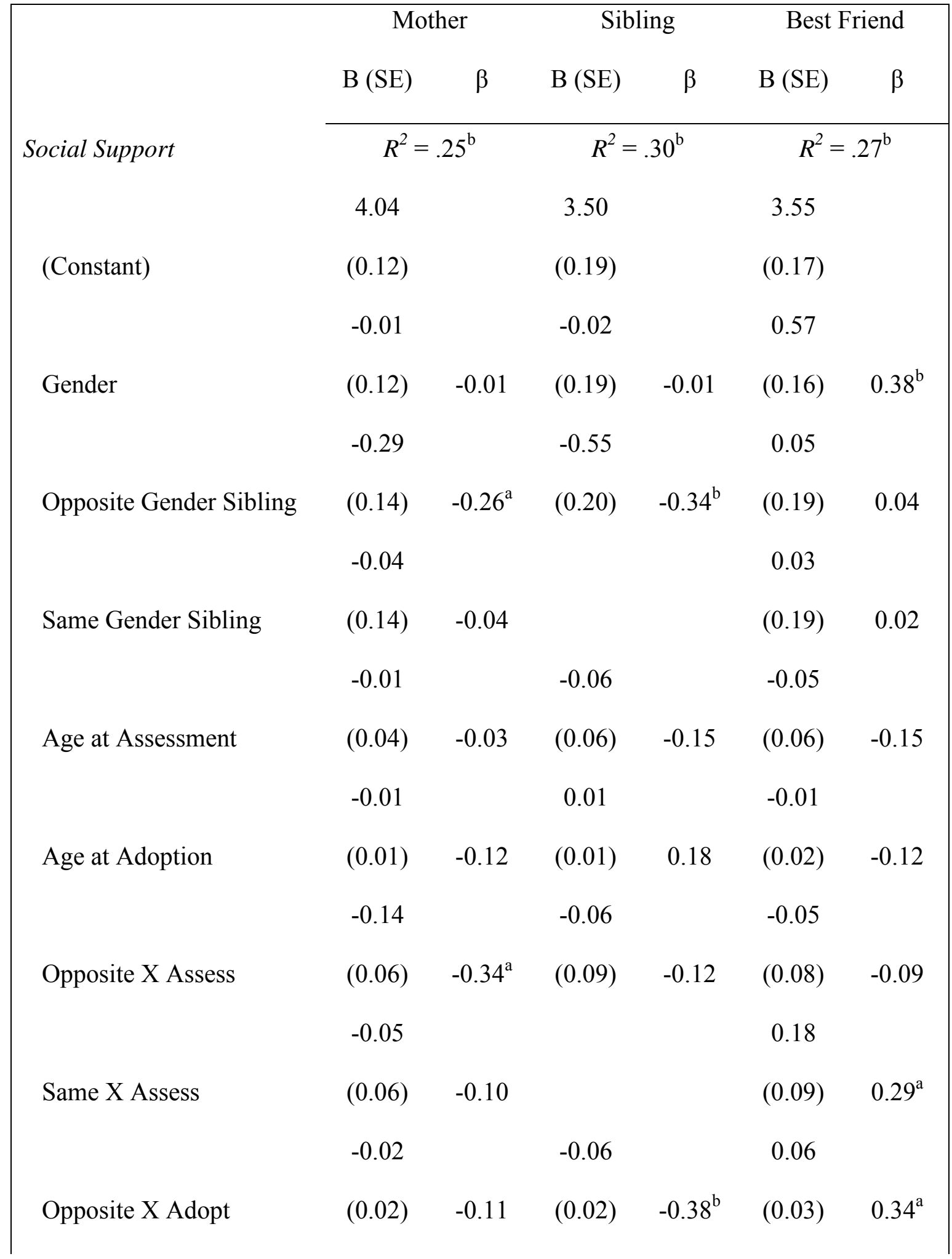




\begin{tabular}{|c|c|c|c|c|c|c|}
\hline & 0.01 & & & & 0.01 & \\
\hline Same X Adopt & $(0.02)$ & 0.14 & & & $(0.02)$ & 0.12 \\
\hline Negative Interaction & $R^{2}$ & 10 & $R^{2}$ & .11 & $R^{2}$ & 12 \\
\hline & 2.44 & & 2.87 & & 1.94 & \\
\hline (Constant) & $(0.19)$ & & $(0.23)$ & & $(0.16)$ & \\
\hline & 0.08 & & -0.08 & & -0.17 & \\
\hline Gender & $(0.18)$ & 0.05 & $(0.23)$ & -0.04 & $(0.14)$ & -0.13 \\
\hline & 0.05 & & 0.08 & & -0.24 & \\
\hline Opposite Gender Sibling & $(0.21)$ & 0.03 & $(0.24)$ & 0.05 & $(0.18)$ & -0.19 \\
\hline & 0.24 & & & & 0.13 & \\
\hline Same Gender Sibling & $(0.22)$ & 0.14 & & & $(0.18)$ & 0.10 \\
\hline & 0.04 & & -0.03 & & 0.05 & \\
\hline Age at Assessment & $(0.06)$ & 0.12 & $(0.08)$ & -0.08 & $(0.05)$ & 0.19 \\
\hline & 0.03 & & -0.02 & & 0.01 & \\
\hline Age at Adoption & $(0.02$ & 0.39 & $(0.01)$ & -0.25 & $(0.02)$ & 0.20 \\
\hline & 0.05 & & 0.03 & & -0.01 & \\
\hline Opposite X Assess & $(0.09)$ & 0.09 & $(0.11)$ & 0.05 & $(0.07)$ & -0.01 \\
\hline & -0.03 & & & & -0.12 & \\
\hline Same X Assess & $(0.10)$ & -0.05 & & & $(0.08)$ & -0.24 \\
\hline & -0.04 & & 0.07 & & -0.04 & \\
\hline Opposite X Adopt & $(0.03)$ & -0.20 & $(0.03)$ & $0.40^{\mathrm{a}}$ & $(0.03)$ & -0.25 \\
\hline Same X Adopt & -0.05 & -0.41 & & & -0.03 & -0.31 \\
\hline
\end{tabular}


Note. Analyses predicting sibling relationship quality included only the dummy variable indicating opposite-gender sibling pairs.

${ }^{\mathrm{a}} p<.05 .{ }^{\mathrm{b}} p<.01$.

\subsubsection{Mother.}

The overall regression predicting mother Social Support was significant, $F(9,79)=2.96, p=$ $.004, R^{2}=.25$. H owever, neither age at adoption nor gender composition was a significant predictor (see Table 8). The overall regression was not significant for mother Negative Interaction, $F(9,79)=0.93, p=.51($ see Table 8$)$.

\subsubsection{Sibling.}

The regression equation predicting sibling Social Support was significant, $F(6,57)=4.14, p=$ $.002, R^{2}=.30$. The change in $R^{2}$ increased significantly for sibling gender composition, $R^{2}$ change $=.10, F(1,61)=6.79, p=.01$, and the interaction of sibling gender composition and age at adoption, $R^{2}$ change $=.10, F(1,57)=7.88, p=.007$. For children with same-gender siblings, age at adoption was not associated with Social Support; but for those with an opposite-gender sibling, older age at adoption was associated with less Social Support (see Table 8 and Figure 4). Although the overall regression predicting sibling Negative Interaction was not significant, $F(6$, $56)=1.15, p=.35, R^{2}=.11$, the $R^{2}$ change was significant for the interaction of sibling gender composition and age at adoption, $R^{2}$ change $=.10, F(1,56)=6.50, p=.01$. When the sibling was the opposite gender, older age at adoption was associated with more Negative Interaction, 
whereas when the sibling was the same gender, age at adoption was not associated with Negative Interaction (see Table 8 and Figure 4).

\subsubsection{Best Friend.}

The overall regression predicting friend Social Support was significant, $F(9,76)=3.10, p=.003$, $R^{2}=.27$. The change in $R^{2}$ increased significantly for the interaction of gender composition and age at adoption, $R^{2}$ change $=.06, F(2,76)=3.08, p=.05$. Holding all else constant, when children had no sibling or a same-gender sibling, age at adoption was not associated with friend Social Support; however, when they had an opposite-gender sibling, older age at adoption was associated with more Social Support (see Table 8 and Figure 4). For friend Negative Interaction, the overall regression equation, $F(9,76)=1.14, p=.35, R^{2}=.12$, was not significant (see Table 8). 

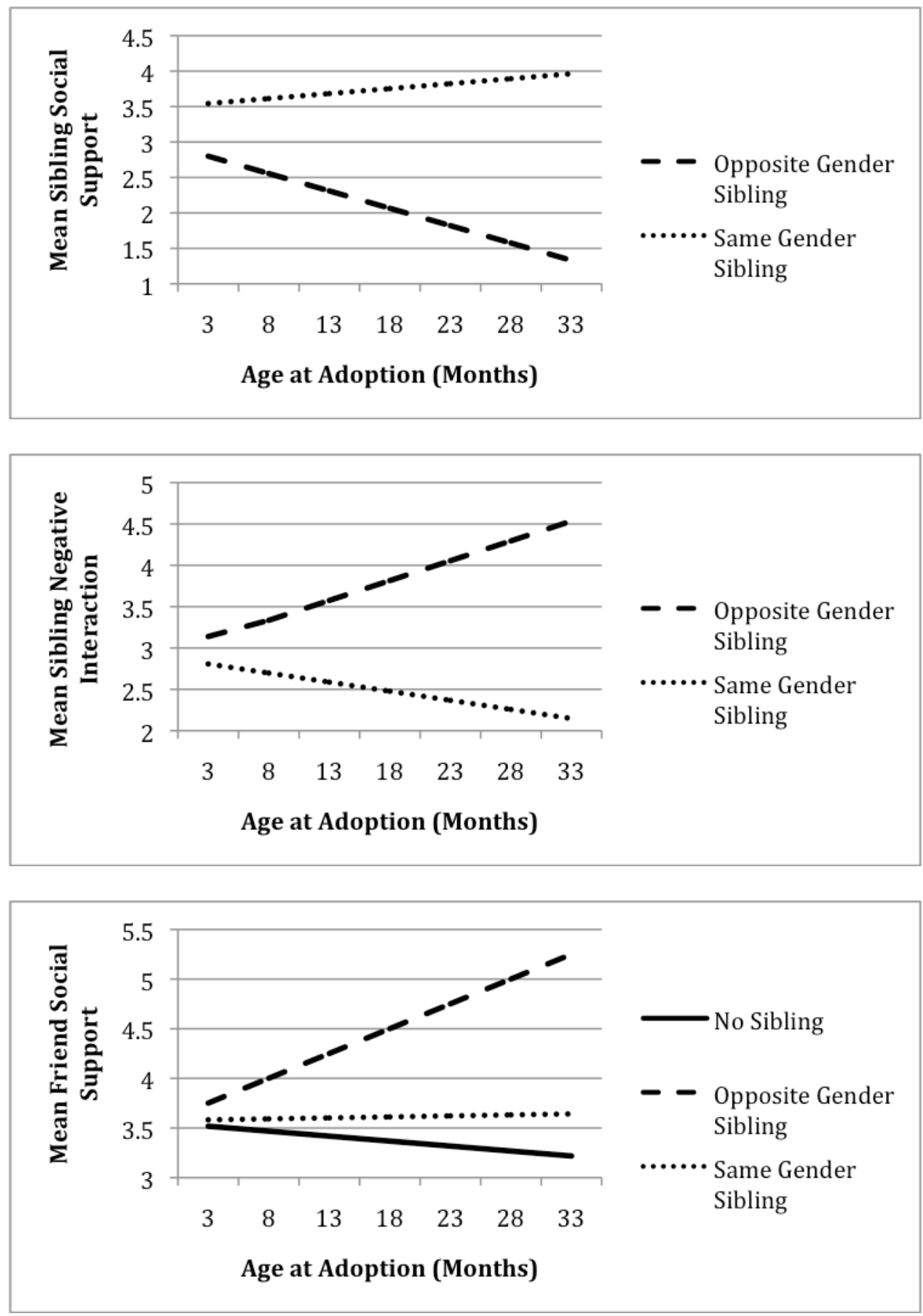

Figure 4. Linear interactions of age at adoption and sibling gender composition for sibling and best friend social support (higher $=$ better) and sibling negative interaction $($ higher $=$ worse), controlling for age at assessment, gender, and interactions. 


\subsection{DISCUSSION}

PI children reported high levels of Social Support and low levels of Negative Interactions in their relationships with mothers, siblings, and best friends. Older ages at adoption were associated with poorer relationship quality with siblings and best friends, but not mothers. Older siblings and same-gender siblings buffered PI children from these negative age-at-adoption effects, especially for relationships with siblings.

\subsection{PI RELATIONSHIP QUALITY}

In the non-PI literature, $22 \%$ of children (aged 9-13) report having no best friend (Parker $\&$ Asher, 1993); however, in the current PI sample, only 3 children (3\%) endorsed having no best friend. Further, PI children reported a similar pattern of relationships for subscale scores across the three referents as non-PI children, except that, contrary to expectations, they generally reported better, not worse, relationship quality than non-PI children (Lempers \& Clarklempers, 1992). Spending time in a Baby Home, especially the lack of response-contingent interactions with a stable attachment figure and inadequate opportunities to develop working models of relationships, was expected to be associated with poorer, not better, relationship quality for PI children. 
As a potential explanation, PI children tend to be conforming and accommodating, at least at younger ages, which may support the creation of relationships; and they may have a greater desire for relationships, given their early social-emotional deprivation. The combination of these factors may allow them to develop higher quality relationships than non-PI children, although this may be limited to earlier adoptees (see below).

Because high quality relationships are related to positive social, academic, and psychological outcomes in non-PI children (e.g., Hartup, 1995; NICHD Early Child Care Research Network, 2009; Yeh \& Lempers, 2004), these positive relationships may similarly buffer PI children from more problems. Although PI children exhibit higher than expected rates of problems, most are within normal limits (Gunnar et al., 2007). Possibly, being reared in an advantaged home with parents and siblings with good social skills and having friends may minimize problems in some PI children that otherwise might occur. Given these findings, future research on PI children should consider relationship quality as a potential moderator of long-term developmental outcomes.

\subsection{AGE AT ADOPTION}

Contrary to findings with parent-reported executive function, behavior problems, and social skills in this sample (Hawk \& McCall, in press; Julian, 2010; Merz \& McCall, in press), an ageat-adoption step-function was not found for relationship quality. Instead, increasing age at adoption was linearly related to increasingly poorer relationship quality (e.g., percentage of children with extremely low sibling social support by age at adoption: $0-5$ months $=0 \%$; $6-11$ months $=3 \% ; 12-17$ months $=10 \% ; 18-23$ months $=20 \% ; 24-48$ months $=25 \%$ ). Attachment 
theory suggests a rather specific age period during which most parent-reared infants develop a relationship with their caregiver (Bowlby, 1982), but the current data do not support such a specific age period. In contrast, Sroufe et al. (1999) propose a cumulative deficiency model, and the current data are more consistent with this conceptualization. Although executive functioning and behavior appear to involve a mechanism in which, after a certain amount of accumulated deficiency, a genetic disposition may be switched on or off (Adele Diamond, personal communication to Robert B. McCall, February 18, 2010), a different developmental mechanism seems to be involved with relationships. Potentially, a much wider window exists for relationships, during which relevant experience is functional. Similarly, there may be more resilience for relationships, such that subsequent relationships can compensate for early deficiency.

Eventually, prolonged institutional exposure does seem to have a corroding effect on relationships, but the effects were not pervasive or consistent, and they were primarily with siblings and best friends, not with mothers. The mother relationship, which was not associated with age at adoption, was expected to have the strongest age-at-adoption effect because of the lack of maternal attachments in the Baby Homes. A potential explanation is that adoptive mothers are more invested in their children than siblings or friends, such that they are more willing to work on having a high quality relationship despite possible difficulties. Similarly, PI children may put more emphasis on the mother relationship because of their lack of attachment in the institution, and there may be a biological drive for a mother-child relationship over siblings and friends. 


\subsection{SIBLING CHARACTERISTICS: HOW SIBLINGS BUFFER INSTITUTIONALIZATION EFFECTS}

The presence of a sibling buffered children from the negative effects of age at adoption on best friend Negative Interactions. Older ages at adoption were related to more friend Negative Interactions for children with no sibling, but not for those with a sibling. As the non-PI literature suggests, children with siblings may learn the skills necessary for high quality friendships, especially in terms of conflict resolution, within their sibling relationships (Franco \& Levitt, 1998; Furman \& Buhrmester, 1985a; Recchia \& Howe, 2009). This practice may be particularly important for later adoptees, who spent a longer time without adequate relationship experiences and who had fewer opportunities to learn social skills early in life.

Older siblings also muted the association between older ages at adoption and poorer relationship quality, consistent with the non-PI literature (Buhrmester \& Furman, 1990; Furman \& Buhrmester, 1985a; Karos et al., 2007). Older siblings may provide a more nurturing environment and be better models than younger siblings. PI children may learn more from older siblings, who are mentally and socially advanced and who may set the ground rules and tone of the sibling relationship, which could be more important for later adoptees, who are more likely to have difficulties. Such learning can occur sooner after adoption when the sibling is older rather than younger than the PI child.

Similarly, PI children with same-gender siblings had higher quality sibling relationships than those with opposite-gender siblings, consistent with the non-PI literature (Buhrmester \& Furman, 1990; Furman \& Buhrmester, 1985a, 1985b). In the current sample, this was a buffering effect, in which children with opposite-gender siblings reported an association between older age at adoption and poorer sibling relationships, but this was not the case for same-gender sibling 
dyads. Same-gender siblings may spend more time together, especially in younger childhood (Furman \& Buhrmester, 1985a), resulting directly in better relationships.

Finally, sibling adoption status was not associated with relationship quality either as a main effect or as a moderator of age at adoption. This finding bodes well for PI children because many adoptive parents are unable to conceive. This suggests that the beneficial effects of having a sibling, especially an older and/or same-gender sibling, are not dependent on the adoption status of that sibling.

\section{$4.4 \quad$ LIMITATIONS}

The current findings are important because they are the first examination of perceived relationship quality in PI children and the moderating effects of sibling characteristics; however, some limitations should be acknowledged. First, the response rate $(22 \%)$ was smaller than expected, resulting in a smaller sample and decreased power. This is a subsample of one of the largest populations of adoptive parents of PI children in the literature (total $N=1117$; current wave $N=417$ ), but the children's response rate could be smaller than parents' because both parent and child needed to cooperate. However, the children who did participate were not significantly different than those who did not, at least on m easures of behavior problems, suggesting that the current sample was not biased toward "good" children or children without behavior problems.

Second, relationship quality consisted of PI children's perceptions, which could have reflected desired quality rather than objective quality; the perspectives of the relationship partner were not collected. The higher relationship quality may reflect a tendency for PI children to 
perceive their relationships as more idealized than non-PI children. However, the children's perception may be the best predictor of outcomes because children act and interpret others' actions based on perceptions (Furman, 1996). Further, the self-report measure was associated with parent-reported behavior problems.

Finally, the current study is cross-sectional, so inferences cannot be made about age changes. Similarly, it could not be determined whether sibling characteristics were causal factors in relationship outcomes or the result of a third variable. Important events and characteristics of the children's lives between adoption and the current data collection were unknown, including aspects of the home life, how much time they spent with siblings when younger, familial social skills, and stressful events (e.g., death of a family member), all of which could have impacted relationship quality. Although these factors will be important to examine in future studies, the current study is unique in that it was one of the first to examine PI relationship quality and the first to suggest that sibling characteristics may moderate institutionalization effects.

\subsection{IMPLICATIONS}

The current findings suggest that resiliency following early deprivation is more possible than previously believed, at least in the domain of relationship quality. Given the nurturing and advantaged adoptive family environment, children with little to no r elationship experience or socio-emotional interactions are able to form high quality relationships, especially with adoptive mothers, even when they were adopted later than 18 months. Thus, the window for learning how to have relationships seems to be larger than originally believed, at least according to child selfreport. 
Further, the sibling relationship seems to promote resiliency in PI children, a topic that had not been examined previously. PI children with siblings presumably have more experience with interactions with children similar to their own age than those without siblings. Older siblings and same-sex siblings may spend even more time together, resulting in more opportunities to practice relationship skills and to develop an understanding of relationships. 


\section{BIBLIOGRAPHY}

Achenbach, T.M \& Rescorla, L.A. (2001). Manual for the ASEBA school-age forms \& profiles. Burlington, VT: University of Vermont, Research Center for Children, Youth, and Families.

Ainsworth, M.D.M., Blehar, M.C., Waters, E., \& Wall, S. (1978). Patterns of attachment. Hillsdale, NJ: Erlbaum.

Ames, E.W. (1997). The development of Romanian orphanage children adopted into Canada. Ottowa: National Welfare Grants.

Armsden, G.C., \& Greenberg, M.T. (1987). The inventory of parent and peer attachment: Individual differences and their relationship to psychological well-being in adolescence. Journal of Youth and Adolescence, 16, 427-455.

Aseltine, R.H., Gore, S., \& Colten, M.E. (1998). The co-occurrence of depression and substance abuse in late adolescence. Development and Psychopathology, 10, 549-570.

Bakermans-Kranenburg, M.J., Steele, H., Zeanah, C.H., Muhamedrahimov, R.J., Vorria, P., Dobrova-Krol, N.A. ... \& Gunnar, M.R. (in press). Attachment and emotional development in institutional care: Characteristics and catch-up. In R.B. McCall, M.H. van IJzendoorn, F. Juffer, C.J. Groark, \& V.K. Groza (eds.), Children without permanent parents: Research, practice, and policy. Monographs of the Society for Research in Child Development.

Berndt, T.J., \& Keefe, K. (1995). Friends' influence of adolescents' adjustment to school. Child Development, 66, 1312-1329.

Boer, F., Versluis-den Bieman, H.J.M., \& Verhulst, F.C. (1994). International adoption of children with siblings: Behavioral outcomes. American Journal of Orthopsychiatry, 64, 252-263.

Bowlby, J. (1982). Attachment and loss: Vol. 1. Attachment. New York: Basic Books. (Original work published 1969)

Branstetter, S.A., Furman, W., \& Cottrell, L. (2009). The influence of representations of attachment, maternal-adolescent relationship quality, and maternal monitoring on 
adolescent substance use: A 2-year longitudinal examination. Child Development, 80, 1448-1462.

Bruce, J., Tarullo, A.R., \& Gunnar, M.R. (2009). Disinhibited social behavior among internationally adopted children. Development and Psychopathology, 21, 157-171.

Buhrmester, D., \& Furman, W. (1990). Perceptions of sibling relationships during middle childhood and adolescence. Child Development, 61, 1387-1398.

Carlson, E. A. (1998), A Prospective Longitudinal Study of Attachment Disorganization/Disorientation. Child Development, 69: 1107-1128.

Cassidy, J. (1994). Emotion regulation: Influences of attachment relationships. Monographs of the Society for Research in Child Development, 59, 228-283.

Cederblad, M., Hook, B., Irhammar, M., \& Mercke, A. (1999). Mental health in international adoptees as teenagers and adults. An epidemiological study. Journal of Child Psychology and Psychiatry, 40, 1239-1248.

Chisholm, K. (1998). A three year follow-up of attachment and indiscriminate friendliness in children adopted from Romanian orphanages. Child Development, 69, 1092-1106.

Dobrova-Krol, N.A., Bakermans-Kranenburg, M.J., van IJzendoorn, M.H., \& Juffer, F. (2010). The importance of quality of care: Effects of perinatal HIV infection and early institutional rearing on preschoolers' attachment and indiscriminate friendliness. Journal of Child Psychology and Psychiatry, 51, 1368-1376.

Erich, S., \& Leung, P. (2002). The impact of previous type of abuse and sibling adoption upon adoptive families. Child Abuse and Neglect, 26, 1045-1058.

Franco, N., \& Levitt, M.J. (1998). The social ecology of middle childhood: Family support, friendship quality, and self-esteem. Family Relations, 47, 315-321.

Furman, W. (1996). The measurement of children and adolescents' perceptions of friendships: Conceptual and methodological issues. In W.M. Bukowski, A.F. Newcomb, \& W. W. Hartup (Eds.), The company they keep: Friendships in childhood and adolescence. Cambridge, MA: Cambridge University Press.

Furman, W., \& Buhrmester, D. (1985a). Children's perceptions of the qualities of sibling relationships. Child Development, 56, 448-461.

Furman, W., \& Buhrmester, D. (1985b). Children's perceptions of the personal relationships in their social networks. Developmental Psychology, 21, 1016-1024.

Furman, W., \& Burhrmester, D. (1992). Age and sex differences in perceptions of networks of personal relationships. Child Development, 63, 103-115. 
Gifford-Smith, M. \& Brownell, C. (2003). Childhood peer relationships: S ocial acceptance, friendships \& peer networks. Journal of School Psychology, 41, 235-284.

Gunnar, M. R. (2001). Effects of early deprivation. In C.A. Nelson \& M. Luciana (Eds.), Handbook of developmental cognitive neuroscience (pp. 617-629). Cambridge, MA: MIT Press.

Gunnar, M.R., Van Dulmen, M.H.M., \& The International Adoption Project Team. (2007). Behavior problems in postinstitutionalized internationally adopted children. Development and Psychopathology, 19, 129-148.

Hair, E.C., Moore, K.A., Garrett, S.B., Kinukawa, A., Lippman, L., \& Michelson, E. (2005). The parent-adolescent relationship scale. In K.A. Moore, \& L. Lippman (Eds.), Conceptualizing and measuring indicators of positive development: What do children need to flourish? (pp. 183-202). New York: Kluwer Academic/ Plenum Publishers.

Hair, E.C., Moore, K.A., Garrett, S.B., Ling, T., \& Cleveland, K. (2008). The continued importance of quality parent-adolescent relationships during late adolescence. Journal of Research on Adolescence, 18, 187-200.

Hartup, W.W. (1995). The three faces of friendship. Journal of Social and Personal Relationships, 12, 569-575.

Hawk, B., \& McCall, R.B. (in press). Specific extreme behaviors of post-institutionalized Russian adoptees. Developmental Psychology.

Hawk, B., \& McCall, R.B. (2011). Age at adoption: A measure of time in the orphanage or child characteristics? Unpublished Manuscript: Authors. University of Pittsburgh Office of Child Development.

Hegar, R.L. (2005). Sibling placement in foster care and adoption: An overview of international research. Children and Youth Services Review, 27, 717-739.

Hodges, J., \& Tizard, B. (1989). Social and family relationships of ex-institutional adolescents. The Journal of Child Psychology and Psychiatry, 30, 77-97.

Hoksbergen, R., Rijk, K., Van Dijkum, C., \& Laak, J.T. (2004). Adoption of Romanian children in the Netherlands: Behavior problems and parenting burden of upbringing for adoptive parents. Developmental and Behavioral Pediatrics, 25, 175-180.

Howe, N., Aquan-Assee, J., Bukowski, W.M., Lehoux, P.M., \& Rinaldi, C.M. (2001). Siblings as confidants: Emotional understanding, relationship warmth, and sibling self-disclosure. Social Development, 10, 439-455.

Juffer, F., \& Rosenboom, L.G. (1997). Infant-mother attachment of internationally adopted children in the Netherlands. International Journal of Behavioral Development, 20, 93107. 
Julian, M. (2010). Social skills in post-institutionalized children. Master's Thesis: Author. University of Pittsburgh.

Karos, L.K., Howe, N., \& Aquan-Assee, J. (2007). Reciprocal and complementary sibling interactions, relationship quality and socio-emotional problem solving. Infant and Child Development, 16, 577-596.

Kerns, K.A., Klepac, L., \& Cole, A. (1996). Peer relationships and preadolescents' perceptions of security in the child-mother relationship. Developmental Psychology, 32, 457-466.

Lansford, J.E., Ceballo, R., Abbey, A., \& Stewart, A.J. (2001). Does family structure matter? A comparison of adoptive, two-parent, biological, single-mother, stepfather, and stepmother households. Journal of Marriage and Family, 63, 840-851.

Le Mare, L., Warford, L., \& Fernyhough, L. (2001). Peer relationships of Romanian orphans 10 years after being adopted to Canada. Poster Presentation: Biennial Meeting of the Society for Research in Child Development; Minneapolis, MI.

Lempers, J.D., \& Clarklempers, D.S. (1992). Young, middle, and late adolescents comparisons of the functional importance of 5 significant relationships. Journal of Youth and Adolescence, 21, 53-96.

Levy, C. (2010, May 4). Russian orphanage offers love, but not new families. The New York Times. Retrieved from http://www.nytimes.com

Lieberman, M., Doyle, A.B., \& Markiewicz, D. (1999). Developmental patterns of security of attachment to mother and father in late childhood and early adolescence: Associations with peer relations. Child Development, 70, 202-213.

Markiewicz, D., Doyle, A.B., \& Brendgen, M. (2001). The quality of adolescents' friendships: Associations with mothers' interpersonal relationships, attachments to parents and friends, and prosocial behaviors. Journal of Adolescence, 24, 429-445.

Mason, C.A., Cauce, A.M., Gonzales, N., \& Hiraga, Y. (1994). Adolescent problem behavior: The effect of peers and the moderating role of father absence and the mother-child relationship. American Journal of Community Psychology, 22, 723-744.

McGue, M., Keyes, M., Sharma, A., Elkins, I., Legrand, L., Johnson, W., \& Iacono, W.G. (2007). The environments of adopted and non-adopted youth: Evidence on range restriction from the sibling interaction and behavior study (SIBS). Behavioral Genetics, 37, 449-462.

Merz, E. C., \& McCall, R. B. (in press). Parent-reported executive functioning behavior in children adopted from psychosocially depriving institutions. Journal of Child Psychology and Psychiatry. 
Nangle, D.W., Erdley, C.A., Newman, J.E., Mason, C.A., \& Carpenter, E.M. (2003). Popularity, friendship quantity, and friendship quality: Interactive influences on children's loneliness and depression. Journal of Clinical Child and Adolescent Psychology, 32, 546-555.

NICHD Early Child Care Research Network. (2006).Infant-mother attachment: Risk and protection in relation to changing maternal caregiving quality over time. Developmental Psychology, 42, 38-58.

NICHD Early Child Care Research Network (2009), Family-Peer Linkages: The Mediational Role of Attentional Processes. Social Development, 18, 875-895.

Parker, J.G., \& Asher, S.R. (1987). Peer relations and later personal adjusment: Are los-accepted children at risk? Psychological Bulletin, 102, 357-389.

Parker, J.G., \& Asher, S.R. (1993). Friendship and friendship quality in middle childhood: Links with peer group acceptance and feelings of loneliness and social dissatisfaction. Developmental Psychology, 29, 611-621.

Pollak, S.D., Nelson, C.A., Schlaak, M.F., Roeber, B.J., Wewerka, S.S., Wiik, K.L., Frenn, K.A., Loman, M.M., \& Gunnar, M.R. (in press). Neurodevelopmental effects of early deprivation in post-institutionalized children. Child Development.

Recchia, H.E., \& Howe, N. (2009). Associations between social understanding, sibling relationship quality, and siblings' conflict strategies and outcomes. Child Development, 80, 1564-1578.

Rutter, M.L., Kreppner, J.M., \& O’Connor, T.G. (2001). Specificity and heterogeneity in children's responses to profound institutional privation. British Journal of Psychiatry, 179, 97-103.

Rutter, M., Sonuga-Barke, E.J., Beckett, C., Castle, J., Kreppner, J., Kumsta, R.... \& Bell, C.A. (2010). Deprivation-specific psychological patterns: Effects of institutional deprivation. Monographs of the Society for Research in Child Development, 75.

Shaw, D.S., Owens, E.B., Vondra, J.I., Keenan, K., \& Winslow, E.B. (1996). Early risk factors and pathways in the development of early disruptive behavior problems. Development and Psychopathology, 8, pp 679-699

Sroufe, L.A., Carlson, E.A., Levy, A.K., \& Egeland, B. (1999). Implications of attachment theory for developmental psychopathology. Development and Psychopathology, 11, 1-13.

Stams, G.J.M., Juffer, F., Rispens, J., \& Hoksbergen, R.A.C. (2000). The development and adjustment of 7-year-old children adopted in infancy. Journal of Psychological Psychiatry and Allied Disciplines, 41, 1025-1037.

The St. Petersburg-USA Orphanage Research Team. (2005). Characteristics of children, caregivers, and orphanages for young children in St. Petersburg, Russian Federation. Applied Developmental Psychology, 26, 477-506. 
The St. Petersburg-USA Orphanage Research Team. (2008). The effects of early socialemotional and relationship experience on the development of young orphanage children. Monograph of the Society for Research in Child Development, 73.

United States Department of State, Office of Children's Issues. Total Adoptions to the United States. Retrieved from http://adoption.state.gov/news/total_chart.html

Van den Dries, L., Juffer, F., van IJzendoorn, M.H., \& Bakermans-Kranenburg, M.J. (2009). Fostering security? A meta-analysis of attachment in adopted children. Children and Youth Services Review, 31, 410-421.

Van den Oord, E.J.C.G., Boomsma, D.I., \& Verhulst, F.C. (1994). A study of problem behaviors in 10- to 15-year-old biologically related and unrelated international adoptees. Behavior Genetics, 24, 193-206.

Verhulst, F.C., Althaus, M., \& Versluis-Den Bieman, H.J.M. (1990). Problem behavior in international adoptees: I. An epidemiological study. Journal of the American Academy of Child and Adolescent Psychiatry, 29, 94-103.

Vorria, P., Papaligoura, Z., Dunn, J., van IJzendoorn, M. H., Steele, H., Kontopoulou, A., \& Sarafidou, J. (2003). Early experiences and attachment relationships of Greek infants raised in residential group care. Journal of Child Psychology and Psychiatry, 44, 12081220.

Vorria, P., Wolkind, S., Rutter, M., Pickles, A., \& Hobsbaum, A. (1998). A comparative study of Greek children in long-term residential group care and in two-parent families: I. Social, emotional, and behavioural differences. The Journal of Child Psychology and Psychiatry, 39, 225-236.

Yeh, H.C., \& Lempers, J.D. (2004). Perceived sibling relationships and adolescent development. Journal of Youth and Adolescence, 33, 133-147.

Zeanah, C.H., Smyke, A.T., Koga, S., Carlson, E. \& the BEIP Core Group (2005). Attachment in institutionalized and community children in Romania. Child Development, 76, 10151028. 